\title{
Molecular Bottom-Up Approaches for the Synthesis of Inorganic and Hybrid Nanostructures
}

\author{
Alberto Escudero ${ }^{1,2, * \mathbb{C}}$, Carolina Carrillo-Carrión ${ }^{2,3}{ }^{(D)}$, Elena Romero-Ben ${ }^{2} \mathbb{(}$, Ana Franco ${ }^{4}$, \\ Christian Rosales-Barrios ${ }^{2}{ }^{-1}, \mathbf{M}^{\text {a }}$ Carmen Castillejos $^{2}$ and Noureddine Khiar ${ }^{2}$ \\ 1 Departamento de Química Inorgánica, Facultad de Química, Universidad de Sevilla, Calle Profesor García \\ González 1, 41012 Seville, Spain \\ 2 Instituto de Investigaciones Químicas (IIQ), CSIC-Universidad de Sevilla, Avenida Américo Vespucio 49, \\ 41092 Seville, Spain; carolina.carrillo@csic.es (C.C.-C.); elena.romero@iiq.csic.es (E.R.-B.); \\ cristian.rosales@iiq.csic.es (C.R.-B.); mcarmen.castillejos@iiq.csic.es (M.C.C.); khiar@iiq.csic.es (N.K.) \\ 3 Departamento de Química Orgánica, Facultad de Química, Universidad de Sevilla, Calle Profesor García \\ González 1, 41012 Seville, Spain \\ 4 Departamento de Química Orgánica, Facultad de Química, Campus de Rabanales, Universidad de Córdoba, \\ Crta. Nacional IV-A, km. 396, 14014 Cordoba, Spain; b12frloa@uco.es \\ * Correspondence: alberto.escudero@csic.es
}

check for

updates

Citation: Escudero, A.;

Carrillo-Carrión, C.; Romero-Ben, E.;

Franco, A.; Rosales-Barrios, C.;

Castillejos, M.C.; Khiar, N. Molecular

Bottom-Up Approaches for the

Synthesis of Inorganic and Hybrid

Nanostructures. Inorganics 2021, 9, 58

https://doi.org/10.3390/

inorganics 9070058

Academic Editor: Paolo Fornasiero

Received: 14 June 2021

Accepted: 14 July 2021

Published: 17 July 2021

Publisher's Note: MDPI stays neutral with regard to jurisdictional claims in published maps and institutional affiliations.

Copyright: (c) 2021 by the authors. Licensee MDPI, Basel, Switzerland. This article is an open access article distributed under the terms and conditions of the Creative Commons Attribution (CC BY) license (https:// creativecommons.org/licenses/by/ $4.0 /)$.
Abstract: Chemical routes for the synthesis of nanostructures are fundamental in nanoscience. Among the different strategies for the production of nanostructures, this article reviews the fundamentals of the bottom-up approaches, focusing on wet chemistry synthesis. It offers a general view on the synthesis of different inorganic and hybrid organic-inorganic nanostructures such as ceramics, metal, and semiconductor nanoparticles, mesoporous structures, and metal-organic frameworks. This review article is especially written for a wide audience demanding a text focused on the basic concepts and ideas of the synthesis of inorganic and hybrid nanostructures. It is styled for both early researchers who are starting to work on this topic and also non-specialist readers with a basic background on chemistry. Updated references and texts that provide a deeper discussion and describing the different synthesis strategies in detail are given, as well as a section on the current perspectives and possible future evolution.

Keywords: synthesis; nanostructures; nanoparticles; mesoporous materials; metal-organic frameworks; sol-gel; colloidal chemistry

\section{Introduction}

The design of chemical strategies for the nanostructuration of materials is one of the basic pillars for the development of both nanoscience and nanotechnology. The term nanostructure is used to refer to structures showing properties that are different to the ones shown in both the molecular and bulk solid state, and in which at least one of their dimensions or structural attributes are in an approximate size range from 1 to 100 $\mathrm{nm}$ [1], although this range can be somehow flexible. Some typical examples of properties shown by nanostructures, depending on their size and shape, are the luminescence in quantum [2-4] and carbon dots [5], the plasmonic properties in metal nanoparticles [6], and the room-temperature ferromagnetism exhibited by nanoparticles of intrinsically nonmagnetic inorganic materials [7]. Nanoscience is thus considered to be situated between atomic and molecular chemistry, and solid state and materials chemistry.

Nanostructures themselves are not advantageous or disadvantageous, when compared to other structures. They are just more appropriate for specific applications, which are connected to the size range between the atomic-molecular and the bulk scales. For example, most of the biomolecular interactions take place within the 1-100 nm size range [8,9]. For this reason, nanostructures are especially relevant in nanomedicine, with applications in imaging, diagnosis, and therapy, among others [10]. In fact, some drug formulations based 
on nanostructures are currently used for the treatment of different cancers [11]. Similar arguments are valid to microelectronics, which specially benefits from the new properties shown by nanostructures, such as quantum conductance oscillations, quantum Hall effects, and resonant tunnelling, among others [12]. Focusing on the chemistry, nanostructured systems are of special relevance in catalysis due to their electronic properties, which are at the frontier between the molecular and metallic states, as well as the high proportion of surface atoms giving rise to numerous active sites. In particular, the inner parts of the walls of nanoporous materials can act as the catalytic sites for redox reactions, and the nanopores of these materials can also serve as hosts for anchoring catalytically active species. In these systems, surface area, pore size, pore volume, and, in general, the solid nanoporosity, play a key role in the catalysed reactions [13]. Examples of relevant reactions catalysed by nanostructures are the reduction in $\mathrm{CO}_{2}$ and $\mathrm{N}_{2}$ to obtain value-added products, such as hydrocarbons, alcohols, and other organic species [14-16], or $\mathrm{NH}_{3}$ [17], the oxidation of $\mathrm{CO}$ [18] and the removal of pollutants [19], and the overall water splitting into hydrogen and oxygen, related to the production of clean fuels [20]. All these features explain how, in the last two decades, the number of available nanostructures has grown exponentially. However, nanostructured materials are nothing new, and many examples of them can be found in nature. What is relatively new is the effort and work of chemists to develop synthetic routes yielding nanostructures with a precise control on their size, shape, and properties [21].

There are two main strategies for the production of nanomaterials. On the one hand, the so-called top-down methods, which are more connected with physical approaches, usually start from large pieces of materials which are divided into smaller pieces through photolithography and other related techniques [22], or mechanochemical approaches [23]. This is probably the most used strategy on an industrial scale due to their relative simplicity, offering a mass-scale production of many nanosystems. However, it is subjected to drastic limitations for dimensions smaller than $100 \mathrm{~nm}$, especially when dealing with the fabrication of electronic integrated circuits [24], and do not provide an exhaustive control on both the structure size and morphology. On the other hand, bottom-up approaches use and combine sub- or nanoscale objects (atoms or molecules, i.e., building blocks) to build up nanostructures, which usually show new or different functions. This approach, which allows a more controlled system design, can be considered as the natural evolution of supramolecular chemistry, which is focused on the intermolecular bonds and covers the structures and functions of the entities formed by association of two or more chemical species [25]. The major limitation of this strategy is the complex chemistry of supramolecular or multicomponent objects, and, in many cases, the difficulties for a large-scale synthesis [26,27].

This review is intended to show a general view on the nanostructuration of inorganic and hybrid inorganic-organic materials, with special emphasis on some strategies for the synthesis of nanostructures from their molecular building blocks. In other words, it will be described how molecular precursors can be used and assembled not only to produce nanosystems but also to control or tune their morphology, aggregation state, polymorphism, surface, crystallinity degree, and other properties, which eventually determine the applications of the nanostructures. In particular, this review is focused on wet chemical syntheses, which are the most used bottom-up approaches for the production of nanostructures, especially nanoparticles (NPs) and mesoporous materials. The main reason for this is that they usually allow a higher control on both kinetics and thermodynamic parameters of the synthetic reactions, and thus a better control over the sizes, shapes, and compositions of the nanostructures [28]. It should finally be considered that, although there are some general trends and some theories about the mechanisms of nanostructure formation, the synthesis of nanostructures is mostly an experimental discipline, meaning that, in most of the situations, the experimental parameters of each reaction have to be adjusted and optimized, as schemed in Figure 1. This review will provide a general view on the synthesis of inorganic and hybrid nanostructures, being especially suitable for 
graduate or undergraduate students, early researchers who start to work on the chemistry of nanosystems, as well as for non-specialist readers who require information on the basics and fundamentals of this experimental discipline. An updated collection of references is given, including more exhaustive and detailed articles in which the synthesis of inorganic and hybrid nanostructures is discussed in detail, being especially appropriate for readers who require a deeper description of this topic. Among them, we especially recommend a recent review by Hunh et al. [29], which covers and explains the synthesis of many different inorganic NPs in detail. A final section on the perspectives and the possible evolution within the synthesis of such nanosystems is also given.

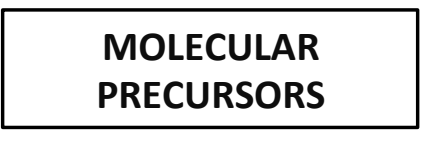

CHALLENGES:

1. Simplicity

2. Upscaling

3. Transfer to the market

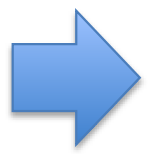

Optimization:

Precursors

Concentrations

Additives

Time, temperature, $\mathrm{pH}$

Solvents

Processes:

Self-Assembly

Condensation

Polymerization

Precipitation

Nucleation

Growth
NANOMETRIC

SYSTEMS

Figure 1. General view on the bottom-up approaches for the synthesis of nanostructures from molecular precursors.

\section{Condensation and Polymerization Reactions: Routes Based on the Sol-Gel Approach}

Sol-gel synthesis is considered as one of the traditional synthetic strategies of inorganic solids, including inorganic polymers and ceramics [30]. Sol-gel syntheses starts with a homogeneous liquid solution of the precursors that undergo hydrolysis and condensation to form both a colloidal suspension (sol) and, later, under appropriate conditions leading to an increase in the viscosity, a gel [31]. Whether gelation or precipitation eventually occurs is dependent on the overall reaction kinetics which can be controlled by reaction parameters such as $\mathrm{pH}$ gradients, relative concentrations of the reactants, temperature, and speed and order of mixing the reactants. Gels are usually favored by slower reaction conditions [32].

Sol-gel routes thus comprise up to five different steps: hydrolysis and polycondensation of molecular precursors, usually metal alkoxides such as tetraethyl orthosilicate (TEOS) and titanium isopropoxide, or other hydrolysable and condensable species [33], followed by aging, drying, and a possible eventual thermal decomposition or calcination (Figure 2) [34]. 


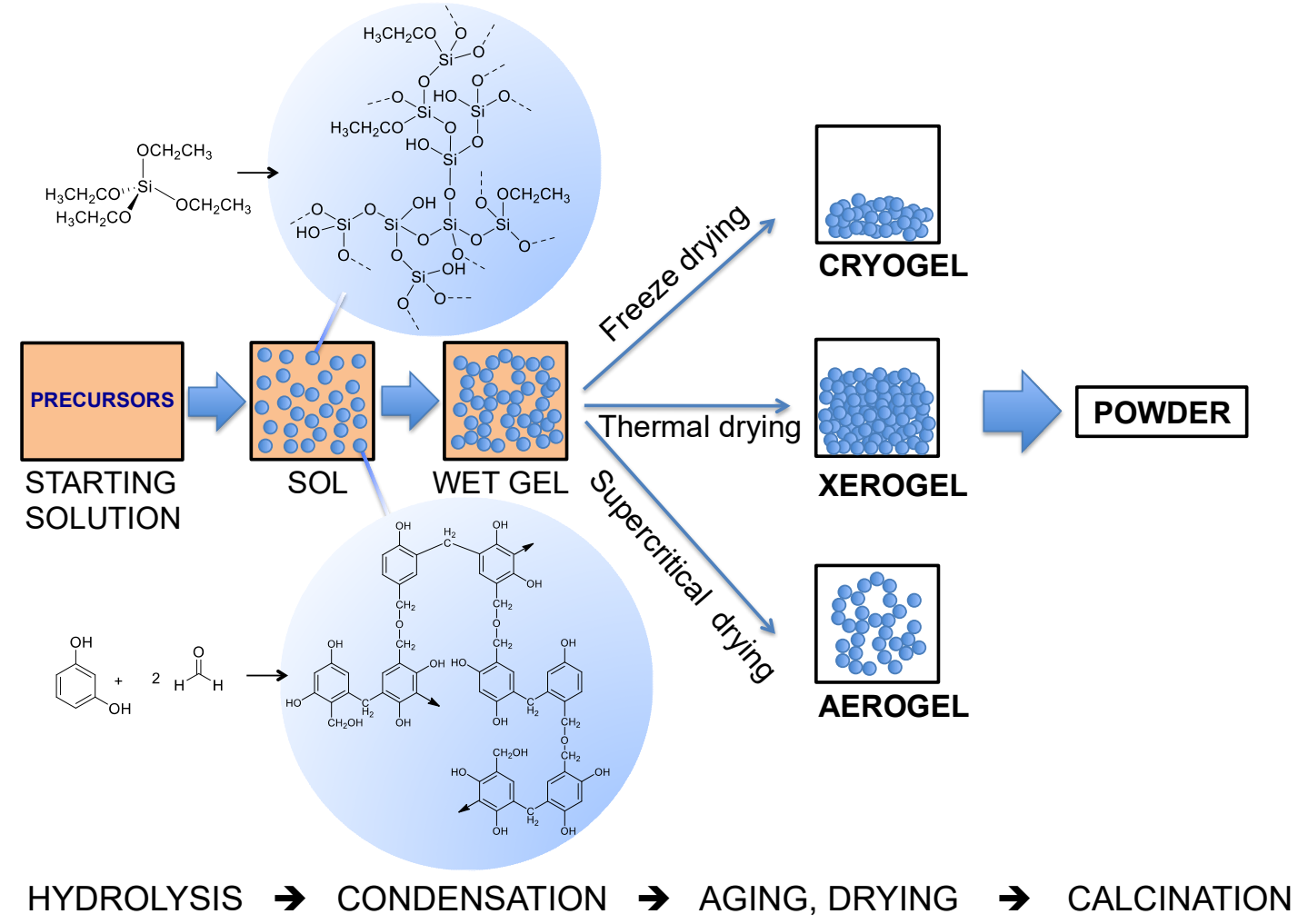

Figure 2. General strategy in the sol-gel synthesis of materials. An appropriate control on the hydrolysis, condensation, and calcination steps may lead to nanostructured materials. Condensation reactions starting from tetraethylorthosilicate (TEOS) and resorcinol/formaldehyde for the synthesis of $\mathrm{SiO}_{2}$ and C-based materials, respectively, are shown. Adapted with permission from [35]. Copyright the Royal Society of Chemistry, 2016.

Although this method is traditionally associated with the synthesis of dense films or particles of widely used inorganic materials such as $\mathrm{TiO}_{2}, \mathrm{SnO}_{2}, \mathrm{WO}_{3}, \mathrm{ZrO}_{2}, \mathrm{SiO}_{2}$, and C-based structures, an appropriate control on some reaction parameters may lead to the production of uniform nanostructures. However, it should be considered that such reaction variables are often complex systems. Possible strategies rely on the design of appropriate precursors and on the use of additives and/or templates. Importantly, the obtained nanostructures should be thermally stable to withstand high temperature post-treatments.

Two of the key parameters during the polymerization and gelation in sol-gel processes are the hydrolysis and condensation. In some cases, uniform nanostructures can be produced by adjusting both hydrolysis and condensation rates. This can be achieved by using the appropriate precursors. In practice, this means that several precursors should be tested and studied systematically to obtain uniform nanostructures. In some cases some general rules may be taken into account. For example, a slow hydrolysis rate, compared with condensation, usually gives rise to more linear polymeric structures and weakly crosslinked gels, whereas a faster hydrolysis is more associated with more isotropic polymeric structures and highly branched clusters. This is well known for silica, in which the acidic or basic catalysts have a significant role in the structure of the resulting gel network [36]. Under some circumstances, the hydrolysis rate can be modified by selecting an appropriate precursor. For example, $1 \mathrm{D}$ metal oxide nanowires of $\mathrm{TiO}_{2}, \mathrm{SnO}_{2}, \mathrm{In}_{2} \mathrm{O}_{3}$, and $\mathrm{PbO}$ can be produced via a sol-gel route starting from metal glycolate, which shows a lower hydrolysis rate than their transition metal alkoxide counterparts [37]. In comparison, faster hydrolysis rate is shown by precursors such as tetra butyl titanate with acidic catalysis which is associated with the production of 3-4 $\mathrm{nm} \mathrm{TiO}_{2}$ nanospheres [38] (Figure 3). 


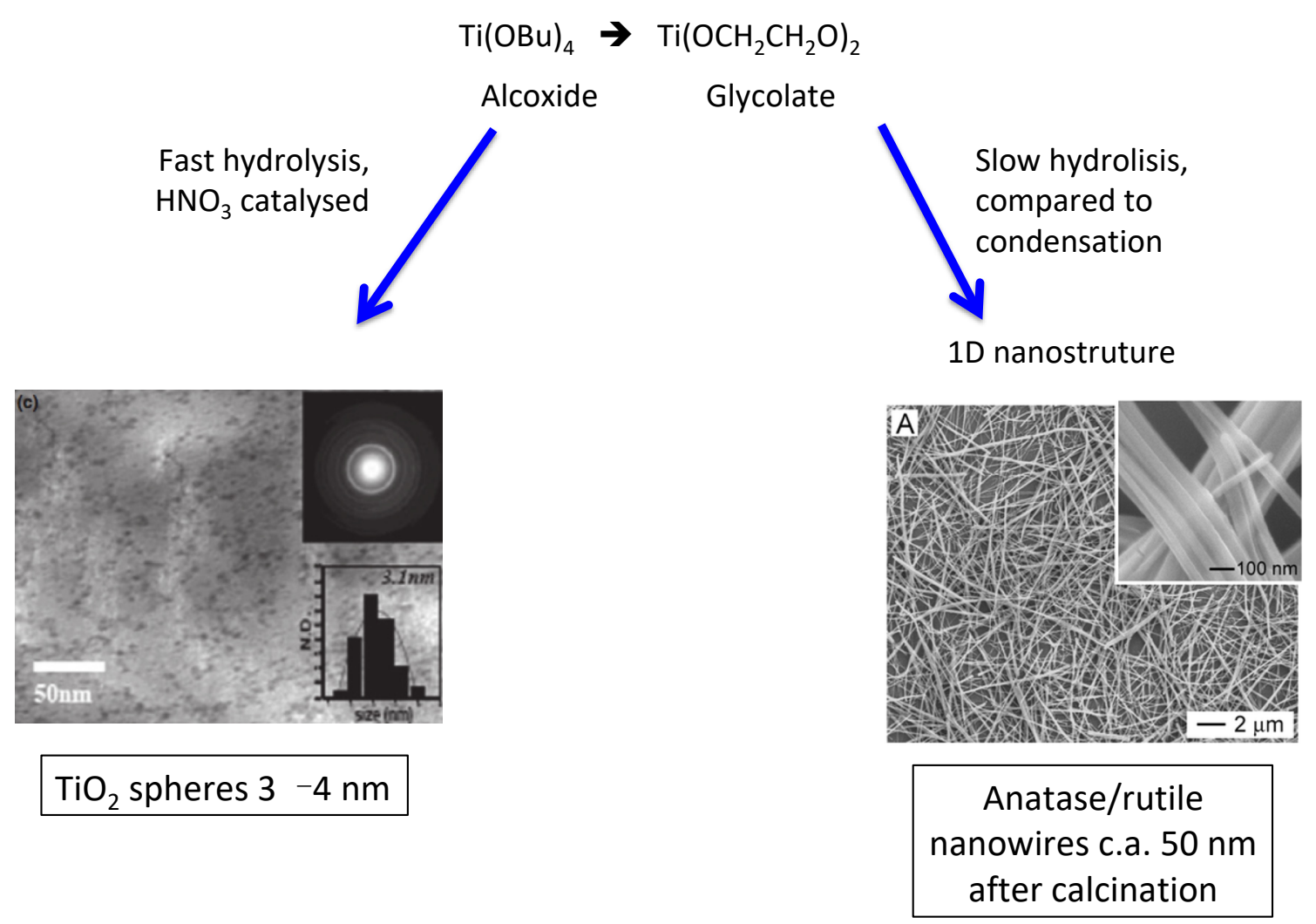

Figure 3. Different $\mathrm{TiO}_{2}$ nanostructures synthesized by the sol-gel from different molecular precursors. Reproduced with permission of [37] (right) and [38] (left). Copyright the Royal Society of Chemistry, 2004, and John Wiley and Sons, 2011.

The use of additives, which can either be small molecules or polymers, is common in sol-gel syntheses. They are normally used to modify the aqueous hydrolysis chemistry of metal ions by forming stable aqueous metal complexes. Citrate, ethylenediaminetetraacetic acid (EDTA), other organic acids, urea, and their mixture (for example citrate and ethylene glycol, base of the Pechini synthesis) are some of the frequently used additives in sol-gel synthesis, showing, in some cases, some applications and advantages within the sol-gel chemistry. From the perspective of nanostructuration and morphology control, it should be considered that the presence of additives during the sol-gel process, including polymers, may create a controlled or hierarchical porosity. After the gel formation, the remaining solvent space between the solid network represents the potential pore space after drying. In fact, the gel formation can be considered as a phase separation process between two heterogeneous phases: a solid network and a solution phase. This phase separation, and thus the eventual porosity of the structure, can, in some cases, be controlled by adding certain additives, and it is determined by their interaction or affinities with both the precursors and the solvent [39]. For example, poly (ethylene oxide) or poly (acrylic acid) are typical polymers used for the synthesis of porous silica [40]. By optimizing the timing between the phase separation and the sol-gel transition, as well as the stability of the different heterogeneous phases, gels with a controlled porous structure can be obtained (Figure 4A). After the removal of the solvent and careful controlled drying that preserve this morphology (i.e., drying with supercritical fluids or freeze drying to obtain aeroor cryo-gels, respectively), followed in some cases by calcination, hierarchically porous monoliths structures with pores resembling the solvent phase and solid architectures can be produced [35] (Figure 4B). 
A

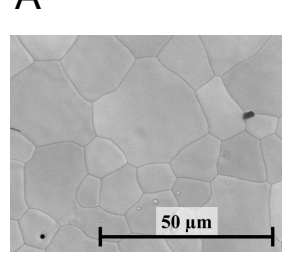

Nonporous struture

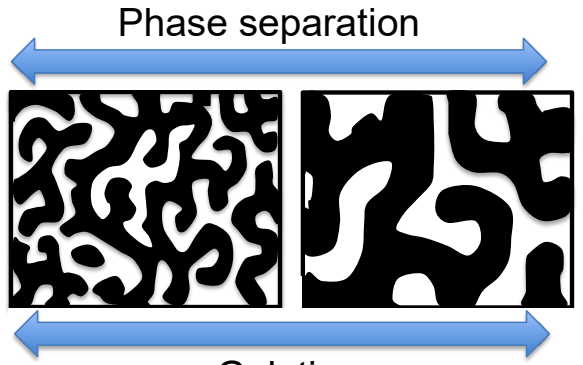

Gelation

Bicontinuous structure
B
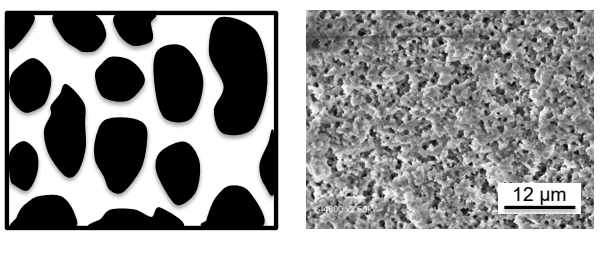

Figure 4. (A) Time evolution of phase-separated domains. Adapted with permission of [41]; Copyright the American Chemical Society, 2006, and taken from [42]. Published by Elsevier. (B) Porous $\mathrm{SiO}_{2}$ silica monolith synthesised in the presence of polyethylene oxide [40]. Published by MDPI.

A step forward in this direction involves the use of templates. Some species can behave beyond an additive and self-organize during the sol-gel process. If the condensation of the sol-gel precursors takes place around such structures, and this template is eventually removed (i.e., by calcination), this geometry can be transferred to the final material, giving rise to structures that usually show an ordered and homogeneous pore distribution (Figure 5A). This is for example the case of mesoporous silica, a family of materials that is characterized by an ordered distribution of the pores, presenting homogeneous sizes between 2 and $20 \mathrm{~nm}$, high pore volume (ca. $1 \mathrm{~cm}^{3} \mathrm{~g}^{-1}$ ), high surface area (ca. $1000 \mathrm{~m}^{2} \mathrm{~g}^{-1}$ ), and has applications in nanomedicine and catalysis [43]. Templates can have a hard or a soft nature. Among the latter, surfactants or other amphiphillic species are frequently employed, which can be easily removed, for example by calcination. The geometry of the mesoporous nanostructure is mostly determined by the self-assembled structure adopted by the specie forming the template. Cationic surfactants, such as cetyltrimethylammonium bromide (CTAB), and amphiphilic block copolymers, such as Pluronics ${ }^{\circledR}$ P103 y F127 (triblock copolymers based on poly ethylene oxide and polypropylene oxide), are employed as templates for the synthesis of mesoporous MCM-41 (with a hexagonal symmetry of the mesoporous structure), SBA-15 (hexagonal), and SBA-16 (cubic cage-structured), respectively. Some TEM images of different mesoporous silica NPs are shown in Figure 5B.
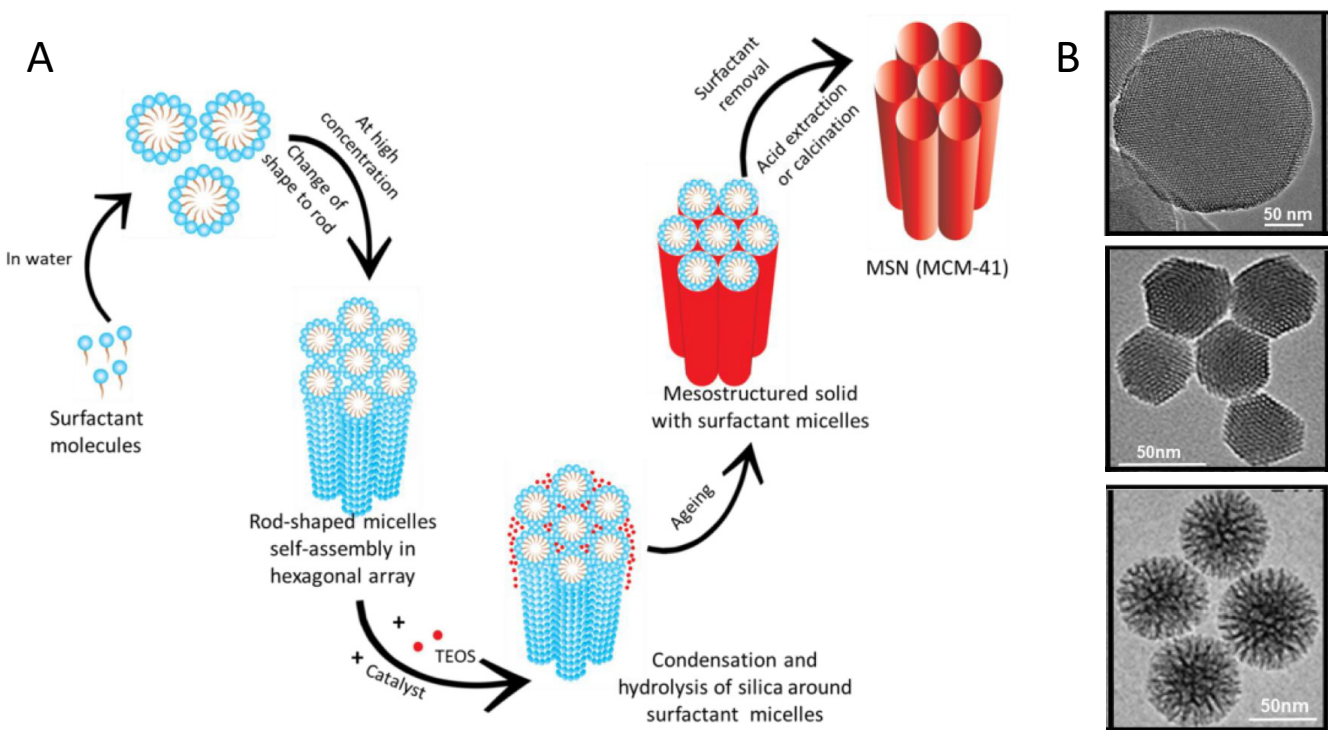

Figure 5. (A): Mechanism of formation of silica mesoporous materials. Taken from [44]. Published by MDPI. (B): TEM micrographs of different mesoporous silica nanoparticles. Reproduced with permission of [43]. Copyright John Wiley and Sons., 2020. 
The most important feature of mesoporous materials is perhaps their ability to incorporate molecules or species into their pores. Molecules of interest can be incubated with the mesoporous materials and, under some circumstances, they may be absorbed onto their porous surface. In the case of mesoporous silica, this process is then controlled by the interactions between such molecules and the remaining surface silanol groups $(-\mathrm{SiOH})$ on the silica [45]. The incorporation of the desired species can also be carried out by designing additional reactions consisting of the condensation of such silanol groups with alkoxyor chloro-silanes containing the additional desired moieties (grafting) [46], although this usually demands harsh reaction conditions. Moreover, an exact and controlled functionalization of the resulting surface may be difficult. An appropriate design of the molecular precursor before the sol-gel synthesis can be used to either provide the structure with additional reactive anchors for subsequent functionalization, or even to better introduce the desired loading group. In both cases, these moieties will be eventually present in the surface of the mesoporous material. To do so, a co-condensation strategy of the original molecular precursors with an optimized amount of a modified one containing the desired moieties can be carried out in the presence of a template, eventually resulting in the incorporation of new anchors such as $\mathrm{N}_{3}$ moieties, suitable for effective conjugation with species containing alkyne groups (example of click chemistry [47]), or in more controlled and homogeneous distribution desired cargo within the mesoporous structure (Figure 6).

In some cases, the term 'ship-in-a-bottle' approach refers to the loading of smaller precursors (active or guest species, usually salts or organometallics) into pre-formed porous host materials via solution-based, gas-phase, or mechanical-mixing impregnation, followed by either thermal/photochemical decomposition or redox reaction (with either strong redox reagents, e.g., hydrazine and $\mathrm{NaBH}_{4}$, or high-temperature treatment in reducing atmosphere, e.g., $\mathrm{H}_{2}$ ) [48]. This approach has been used for the preparation of hybrid composite nanostructures based on zeolites [49-51] and MOFs [52], with applications in gas separation, $\mathrm{CO}_{2}$ capture, and catalysis, among others. On the other hand, the opposite "bottle around ship" or "templated synthesis" approach consists of the assembly of the host material around the active or guest species $[53,54]$.

Particular examples of templates are solid particles that can be easily dissolved under appropriate conditions. This is in fact a strategy for the synthesis of silica capsules, in which the molecular precursor, usually TEOS, is condensed on sacrificial $\mathrm{CaCO}_{3}$ particles. These cores can be eventually dissolved in mild conditions, giving rise to $\mathrm{SiO}_{2}$ capsules in which different molecules can be incorporated, with typical applications in drug delivery [57,58]. Hybrid organic-inorganic materials are also accessible by sol-gel chemistry. For example, sol-gel polymerization of silica and titania alkoxides, and others, on previously formed chitosan hydrocolloids or spheres can be used for the synthesis of chitosan- $\mathrm{SiO}_{2}$ and $\mathrm{TiO}_{2}$ hybrid materials yielding, after supercritical drying, high-surface-area porous materials with reactive surface and applications in catalysis $[59,60]$.

Phase separation induced by the presence of additives and templating strategies combined with sol-gel processing can be used for the synthesis of porous nanostructured ceramics. For example, different porous structures of metal oxide systems such as $\mathrm{Ce}_{0.5} \mathrm{Mg}_{0.5} \mathrm{O}_{1.5}, \mathrm{CeO}_{2}, \mathrm{Mn}_{3} \mathrm{O}_{4}$ and $\mathrm{Fe}_{2} \mathrm{O}_{3} / \mathrm{Fe}_{3} \mathrm{O}_{4}$ synthesized through a Pechini-type approach can be produced by adjusting the malic acid and glycerine ratio, which are used as additives, in the presence of a poly(methyl methacrylate) (PMMA) colloidal crystal template. The resulting structures range from microspheres to bicontinuous networks and three-dimensionally ordered macroporous (3DOM) materials. In this case, the degree of polymerization of the polyester network, which can be controlled through tailoring the reagent imbalance, was assigned to be the predominant controlling factor of the system microstructural evolution [61]. 


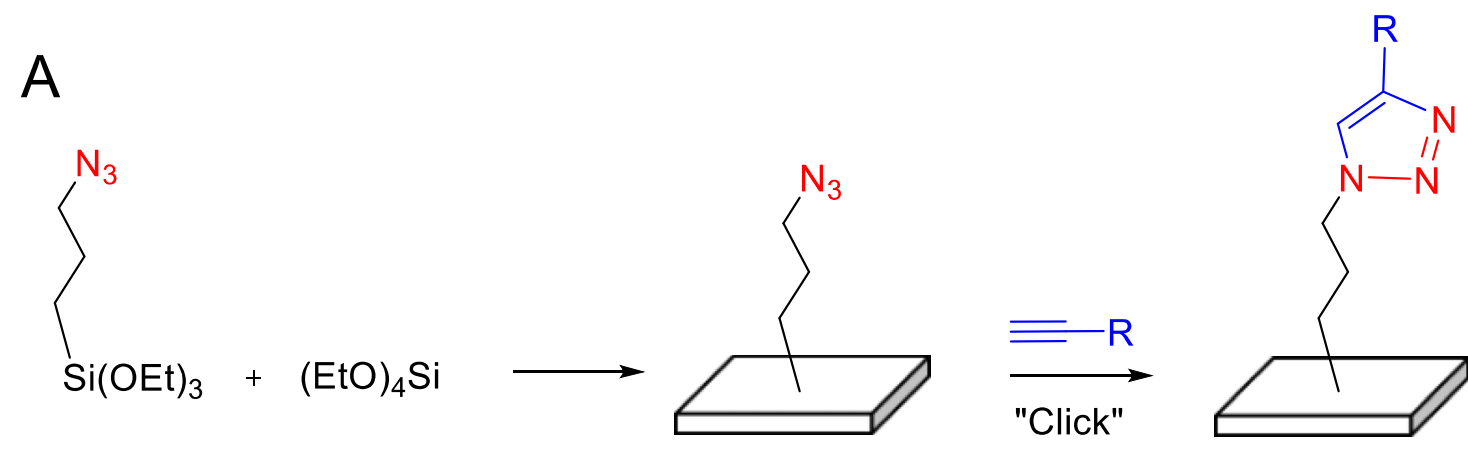

B

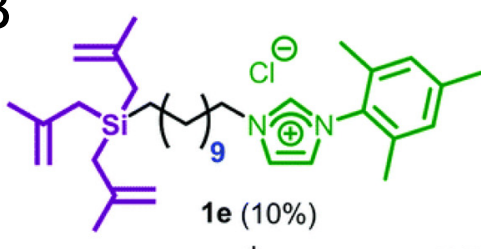

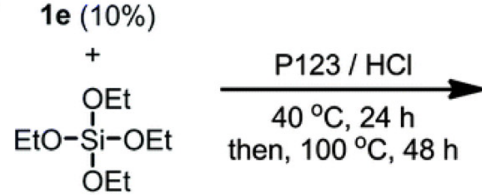
$(90 \%)$
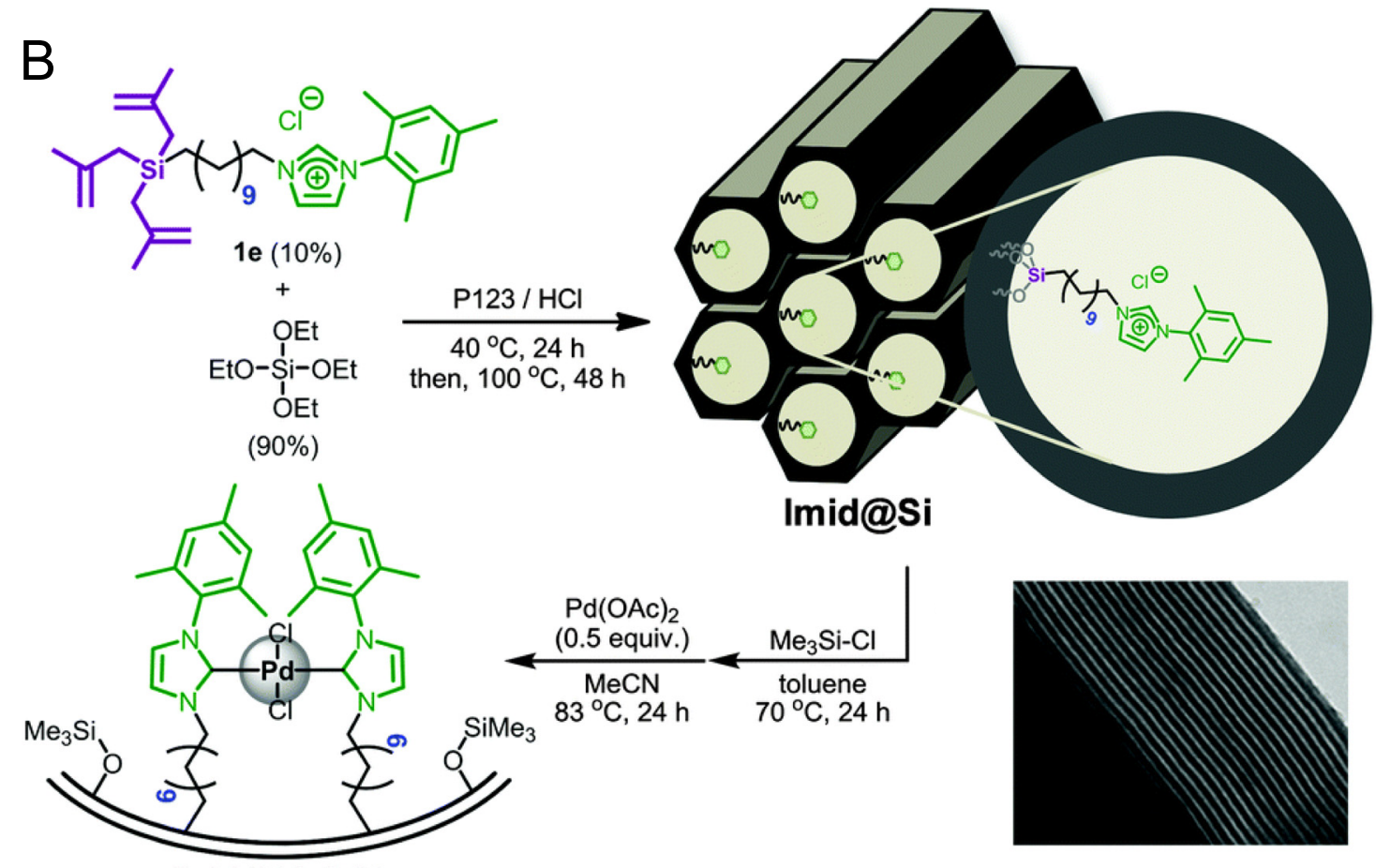

Pd-NHC@Si

Figure 6. (A) Co-condensation strategies for the synthesis of mesoporous silica nanoparticles with controlled and homogeneous $\mathrm{N}_{3}$ anchors for further click functionalization. Adapted with permission of [55]. Copyright the American Chemical Society, 2012, and (B) bulky organic groups such as imidazolium groups that can be used for a more controlled absorption of Pd. Reproduced with permission of [56]. Copyright the Royal Society of Chemistry, 2015.

\section{Colloidal Synthesis of Nanostructures}

The colloidal chemistry is a powerful method for the synthesis of many different nanostructures, including metal, semiconductor, and oxide NPs. In this strategy, NPs are formed in solution, which usually offers a great control on their shape and size, allowing in many cases a narrow size distribution [62]. Moreover, synthesis methods for the production of anisotropic particles [63] as well as complex structures such as hollow structures [64], core-shell particles [65], and particles showing regions with different surfaces, chemistries, and properties (for example Janus NPs [66]) can be designed. The major drawback of this strategy is the possibility of particle aggregation. Colloids are defined as dispersions of one material, typically particles or droplets in a size range from $1 \mathrm{~nm}$ to $1 \mu \mathrm{m}$, in another substance, which can be solid, liquid, or gas [67]. Colloids are thermodynamically unstable with respect to the bulk, and particles tend to agglomerate and aggregate. However, colloidal particles may be stabilized by either binding long-chained molecules to the particle surface, giving rise to steric repulsion and solubilization in non-polar solvents, 
or by surface charge stabilization, which may give rise to electrostatic repulsion of the particles. For this reason, colloidal inorganic NPs may be considered as hybrid inorganicorganic systems consisting of an inorganic core and an organic shell. The presence of this surface organic shell, and especially the possibility of doing surface chemistry with it (i.e., functionalization) [68], is maybe one of the most interesting features of such structures.

The classical nucleation and growth model, developed by Lamer in the 1950s for colloidal sulfur [69], is traditionally used to explain the synthesis of colloidal particles from a solution. It considers the evolution of the reactant (or atom) concentrations with time, describing three different phases: saturation and increase in the precursor concentration, nucleation of very small particles, and particle growth. This model establishes that the separation of nucleation and growth processes are necessary to obtain monodisperse particles by homogeneous precipitation, and that some variables, such as the precursor concentrations, number of formed nuclei, and viscosity of the media and temperature (which affect diffusion), can be optimized for a better control on the final morphology of the NPs. A more detailed explanation of this model is given in the section dedicated to metal-organic frameworks.

Solid nuclei can be produced either by reduction or decomposition of a precursor. The former is usually employed for the synthesis of metallic plasmonic NPs. In this case, the reduction in precursors such as $\mathrm{HAuCl}_{4}, \mathrm{AgNO}_{3}$ or $\mathrm{Pt}(\mathrm{acac})_{2}$ with sodium citrate, sodium borohydride, sodium ascorbate, or sodium thiosulfate, among others, gives rise to solid metal nuclei. Although the strong or mild nature of the reductant may have an influence, additives usually play a key role in the final morphology of the plasmonic particles, acting as shape-directing reagents [70]. For example, the presence of species such as $\mathrm{CTAB}$, polymers, and even halide anions during the growth step of the synthesis may lead to anisotropic nanoparticles by either inducing kinetically controlled NPs growth or blocking some growing facets [71]. For these systems, the nucleation and growth are, in many cases, separated in two different synthetic steps. This is known as the seed-mediated strategy, which usually avoids additional nucleation events and thus provides a better control on the particle morphology through a more controlled reaction kinetics [72,73]. Typical synthesis of plasmonic NPs [74] can be performed in both aqueous [75,76] or organic solvents [77]. The latter usually offers higher possible synthesis temperatures, higher precursor concentrations, as well as a wider selection of hydrophobic additives, which may better stabilize or control the morphology (i.e., capping) of the NPs, although they render hydrophobic NPs which may demand additional post-synthetic treatment. Some $\mathrm{Au}$ and Ag NPs with different morphologies are shown in Figure 7. For example, the deposition of gold onto previously formed gold seeds by reduction with ascorbic acid of solutions containing $\mathrm{HAuCl}_{4}, \mathrm{CTAB}$ and small amounts of $\mathrm{AgNO}_{3}$ gives rise to gold nanorods, while the concentration of the additive poly(vinylpyrrolidone) (PVP) or the $\mathrm{pH}$ controls the morphology of silver NPs. 


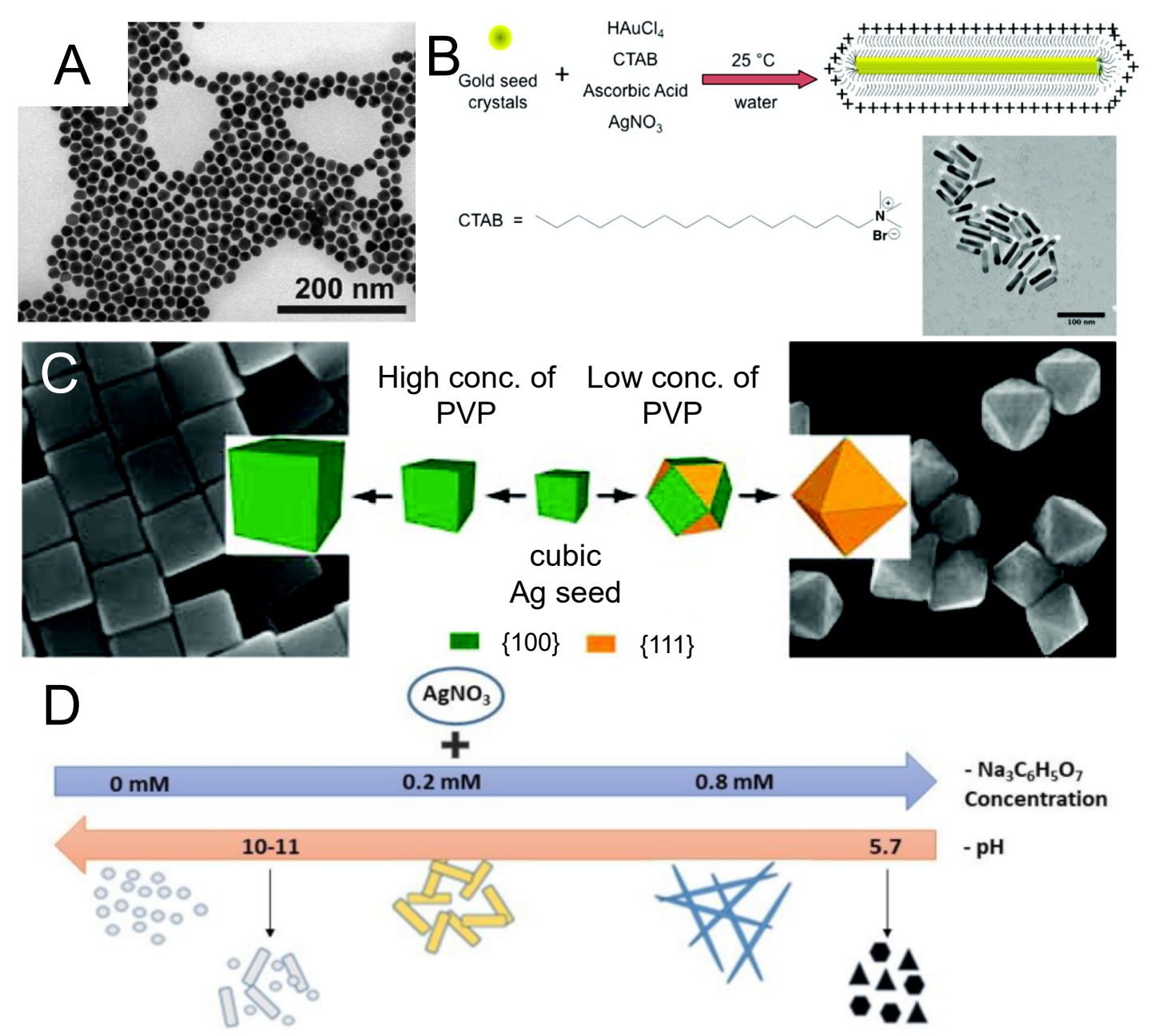

Figure 7. (A) Spherical Au NPs synthesized in water using sodium citrate as a reductant. Reproduced with permission of [75]. Copyright the American Chemical Society, 2011. (B) Au nanorods synthesized in water in the presence of CTAB. Reproduced with permission of [78]. Copyright the American Chemical Society, 2010. (C) Ag NPs with cubic and cuboctahedral shapes synthesized in ethylene glycol in the presence of different amounts of poly(vinylpyrrolidone) (PVP). Reproduced with permission of [79]. Copyright the American Chemical Society, 2011. (D) Ag NPs of different morphologies synthesized in water at different $\mathrm{pH}$ in the presence of different amounts of sodium citrate. Taken from [80]. Published by MDPI. All the syntheses correspond to seed-mediated strategies.

Precursor decompositions constitute the second group of strategies for the formation of solid nuclei. Such reactants usually release cations or anions into the solution, causing precipitation. As a general rule, the synthesis of uniform NPs requires a slow and controlled release or cations or/and anions into the reacting media, followed by an appropriate kinetics [81], which may be determined after the experimental optimization of the reaction conditions. This is the basic of the homogeneous precipitation. The molecular design of the precursor is often a key factor in the synthesis of uniform nanostructures, given that, apart from the slow and controlled release of the cations or anions, it may prevent uncontrolled decompositions and precipitations and second nucleation events, and may also provide colloidal stability to the precipitated nuclei. This is relevant in the synthesis of metal or metal oxide NPs through the organometallic approach, which uses organometallic and metal-organic complexes as precursors. Nanostructures are formed when the precursors decompose in the presence of appropriate ligands, whose amount is also optimized [82]. For example, the decomposition of bis(dibenzylideneacetone)platinum ( $\left[\mathrm{Pt}(\mathrm{dba})_{2}\right]$, a neutral $\mathrm{Pt}$ complex) at $-80{ }^{\circ} \mathrm{C}$ with $\mathrm{H}_{2}$ in the presence of controlled amounts of $\mathrm{N}$-heterocyclic thiones (NHT) is used for the synthesis and stabilization of approxi- 
mately $2 \mathrm{~nm}$ Pt NPs. Sub-stoichiometric amounts of the ligands prevent the formation of a new organometallic compound, induce aggregation and thus lead to the precipitation of small Pt NPs (Figure 8A) [83]. Other examples are the synthesis of highly monodisperse Sn NPs, which are produced after the reduction in a Sn-oleylamido complex, previously designed from the reaction of lithium oleylamide and $\mathrm{SnCl}_{2}$ (Figure 8B) [84]. In many cases, highly uniform NPs can be synthesized in organic solvents of high boiling points such as octadecene, in the presence of oleic acid, oleylamine, or mixtures or analogous additives $[85,86]$, although it should be noticed that the resulting particles are hydrophobic. Analogously, a Cd-hexylphosphonic acid (HPA)/trioctylphosphine oxide (TOPO) complex synthesized from $\mathrm{CdO}$ is the appropriate precursor to obtain uniform semiconductor CdSe NPs, given that it is more prone to a controlled decomposition and is also suitable for larger-scale synthesis (Figure 8C) [87].

A<smiles>[R]n1ccn([R])c1=S</smiles>
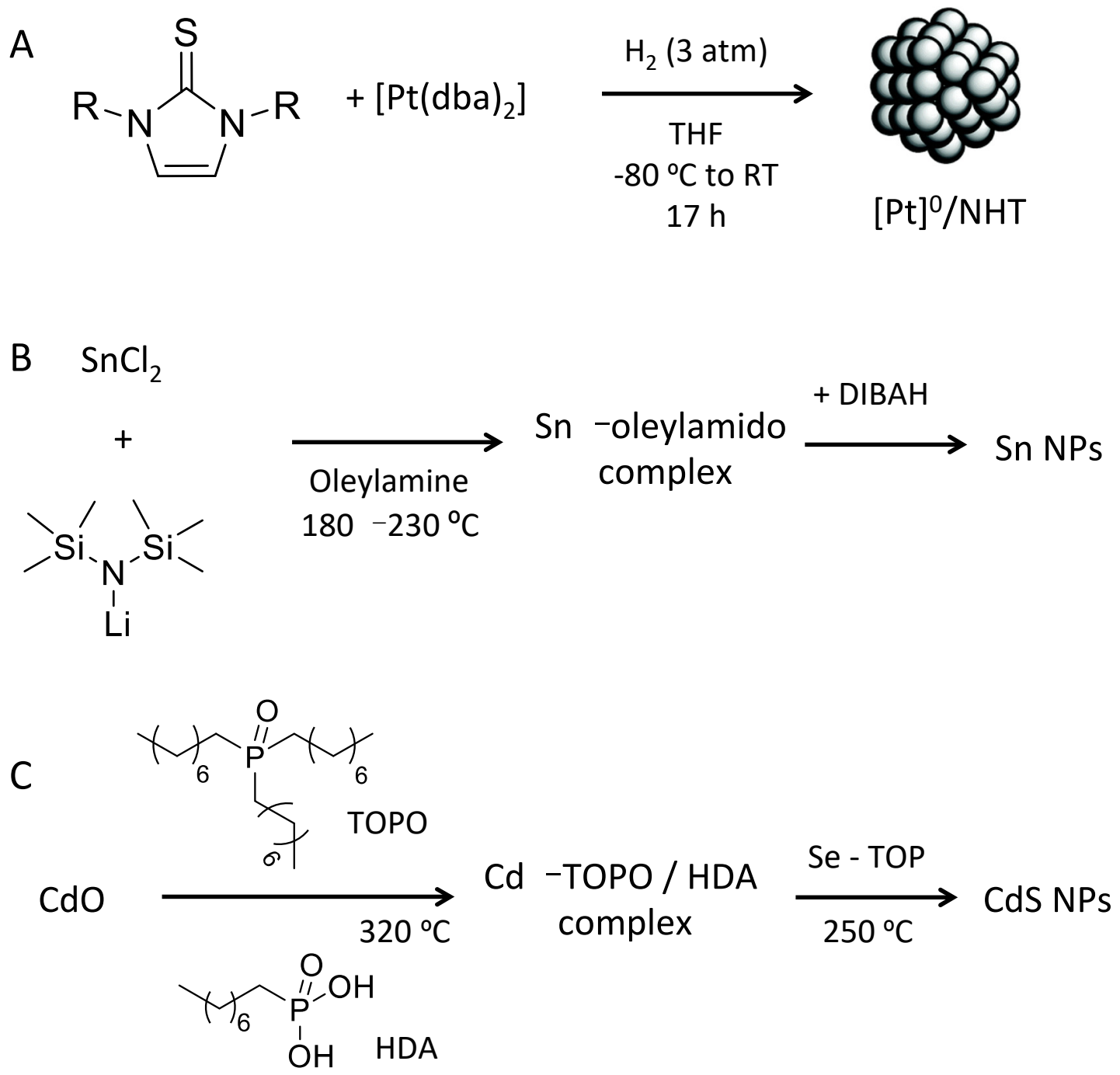

Figure 8. (A) Organometallic approach for the synthesis of small Pt NPs from an appropriate bis(dibenzylideneacetone) platinum complex in the presence of N-Heterocyclic Thiones (NHT). Taken from [83]. Published by the Royal Society of Chemistry. (B) Synthesis of uniform Sn NPs from $\mathrm{SnCl}_{2}$ and lithium bis(trimethylsilyl)amide in the presence of oleylamine. The resulting Sn-oleylamido complex is reduced with diisobutylaluminium hydride (DIBAH) [84]. (C) Synthesis of uniform CdS semiconductor NPs from a Cd-trioctylphosphine oxide (TOPO)/hexylphosphonic acid (HPA) complex. The NPs are formed after the addition of a Se-trioctylphosphine selenide (TOP) solution [87].

Molecular species such as yttrium acetylacetonate (Y(acac) $)_{3}$ [88,89] and sodium tetrafluoroborate $\left(\mathrm{NaBF}_{4}\right)$ [90] are appropriate precursors for the synthesis of Y-based 
fluoride NPs by homogenous precipitation, since the $\mathrm{Y}^{3+}$ and $\mathrm{F}^{-}$ions are slowly released upon heating. Ionic liquid are good alternatives, as they can either act as precursors (for example, the ionic liquid 1-butyl-2-methylimidazolium tetrafluoroborate) (BMIMBF 4 also releases slowly fluoride anions when heating), and solvents [91,92]. In other cases, metal complexes can be formed, as it occurs for calcium citrate complexes, which also slowly release $\mathrm{Ca}^{2+}$ into the solution at elevated temperature [93], and rare earth-citrate complexes [94,95], used as precursors for the synthesis of uniform rare earth-based NPs.

Other synthetic variables that may be taken into account are the presence and concentration of additives, which may also act as capping and/or dispersing agents and may thus play a role in the final morphology of the NPs [70]. For example, similar to the synthesis of anisotropic metal NPs, the presence of CTAB in the reaction media has been associated, in some cases, with the synthesis of anisotropic ceramic nanostructures, as it is the case of strontium hydroxyapatite nanorods [96-98]. At this point, the additives should show some affinity for the NPs surface. For example, the surface of Au and Ag NPs and other plasmonic materials show affinity toward additives containing thiols, amines, and cyanides; species containing carboxyl and hydroxyl groups are usually appropriate for oxides, whereas molecules with thiols, hydroxyl, and amino moieties may be appropriate for semiconductor NPs [68]. In some cases, additives do not only act as structure directing species, but also as functionalizing agents, provided they are eventually situated on the NP surface (in some cases the term "one-pot" synthesis is used to refer this) [99]. This may prevent NPs from aggregation, thus enhancing their colloidal stability, and also offer reactive anchors on the NP surface for conjugation with additional functional species.

The reagent concentrations, the synthesis temperature, the $\mathrm{pH}$ of the reaction, the heating method (microwave or conventional oven), and the solvent composition are other variables that may play a key role in the optimization of the synthesis routes yielding uniform NPs $[100,101]$. Solvents such as polyols may give rise to changes in both the diffusion and dielectric constant of the reaction media; in some cases, they can prevent uncontrolled precipitation by forming stable complexes with the metals [102], as well as act as reducing agents, as in the case of the synthesis of Ag NPs [103].

Syntheses at atmospheric pressure can be performed in water or organic solvents such as alcohols, polyols, and solvents of higher boiling points at a temperature below the boiling point of the solvent, whereas hydro- or solvothermal-based methods are those carried out in closed vessels under autogenous pressure above the boiling point of the solvent [104]. They have been applied for the synthesis of many different nanomaterials [105]. Ionothermal syntheses use ionic liquids simultaneously as both the solvent and potential template or the structure-directing agent in the formation of solids, and have been applied for the synthesis of porous materials such as zeolites, MOFs, and inorganic-organic hybrid nanostructures $[106,107]$. Mechanochemical processes use mechanical forces such as compression, shear, or friction for the synthesis of materials, and have recently emerged as an alternative to traditional routes for nanomaterials preparation [108].

\section{Synthesis of Metal-Organic Frameworks (MOF)-Based Nanomaterials}

Metal-organic frameworks (MOFs), a representative family of hybrid inorganicorganic materials, are currently one of the hot topics in the field of hybrid porous solids [109] Although MOFs were discovered back in 1965, the acronym "MOF" was first introduced by Yaghi and co-workers in 1999 [110], and it was after their studies that highlighted the true potential of these materials when MOFs started to attract great interest. MOFs, also called porous coordination polymers, are self-assembled structures composed of metal nodes (metal ions or clusters) and polydentate organic ligands (mainly carboxylates, imidazolates, or phosphonates) [111-113]. They are obtained via "reticular synthesis", a bottom-up synthetic approach in which predetermined ordered structures are produced by selecting the appropriate molecular building blocks. The resulting ordered structural motifs, similar to cage-like structures, provide them with a high internal surface area and porosity, which are the key features exploited in most of their applications in fields as diverse as gas storage 
and separation [114-116], molecular sieving [117], energy storage and conversion [118], sensing [119], catalysis [120], and controlled delivery of active species (e.g., drugs [121,122] and fertilizers [123]).

The synthetic process generally consists of mixing the molecular building blocks (i.e., precursors) in a solvent (commonly methanol, dimethylformamide, or water); it then either leaves the mixture undisturbed at room temperature during a period of time when the self-assembly process takes place, or heats the mixture by conventional heating or through other energy sources, such as microwave or ultrasound, at an appropriate temperature and for a specific time. The incorporation of a modulator agent (i.e., additive) into the synthetic mixture is a common strategy to achieve a fine control over the self-assembly process, and in ensuring reproducibility of the physical properties such as crystallinity, particle size, morphology, porosity, defectivity, and surface chemistry of MOFs [124], as it will be shown later with some illustrative examples. It should also be noted that, as in colloidal synthesis, the experimental conditions (e.g., metal-to-ligand ratio, metal source, solvent, presence of bases or $\mathrm{pH}$, capping agent, temperature, and reaction time) have a strong influence on the final structure of the MOFs, as well as on their physicochemical properties. Thus, the rational synthesis of MOFs requires a careful choice of synthetic strategies, and the optimization of the experimental parameters. It is also important to remark that the ease of synthesis of many MOF's types is a large bonus, which makes them attractive alternatives to the traditional porous materials.

A special feature of MOFs associated with their modular nature is their wide tunability. The topologies, porosities, functionalities, and surface properties of MOFs can be manipulated by playing with different metal nodes and organic linkers, and also by means of post-synthetic modifications [125]. Indeed, nowadays, they are a huge family of MOFs with about 20,000 different structures (as reported in the Cambridge database [113]) and with quite diverse properties, which can be predefined on purpose thanks to the help of computational studies. This is possible because of the periodic structure of crystalline MOFs that allows one to know precisely the position that each atom within the crystal lattice and, therefore, its coordination environment, bond distances, electronic properties of metal ions, etc. [126]. Computational methods are nowadays used not only to understand the formation and ultimate properties of MOFs, but also to predict some properties, as well as establishing structure-activity relationships. Moreover, in the catalysis field, these computational methods are a powerful tool for explaining reaction mechanisms and observed selectivities, among other aspects.

Despite the tremendous growth in the number of MOFs synthesized to date, the mechanism of MOF formation is not yet fully understood. In order to control the structures and functionalities of MOFs, it is really important to understand the interactions between the constituent building blocks and the physical factors governing the self-assembly process [127]. Several experimental and theoretical studies have pointed out that the selfassembly process of a MOF system is a stochastic and multistage ordering process [128], and that multiple intermediates can be formed during this process $[129,130]$. Despite this, from a simplified point of view, the LaMer model for the synthesis of colloidal particles can also be applied to explain the formation of MOF particles in solution (Figure 9). As stated previously in Section 3, the process consists of two stages, namely nucleation and growth During the initial state of nucleation, the concentration of the reactive species increases until reaching the critical concentration of nucleation $\left(C_{\text {nuc }}\right)$. After this point, the reactive species start to assemble and form nuclei, which results in a decrease in monomers in the solution. Afterwards, the growth of the particles takes place, and the size increases with time. Eventually, the system reaches the saturation point $\left(C_{\text {sat }}\right)$, at which point the growth and solvation of particles reach equilibrium. The nucleation stage is critical in controlling the size of MOF particles; rapid formation of nuclei leads to smaller MOF particles. 


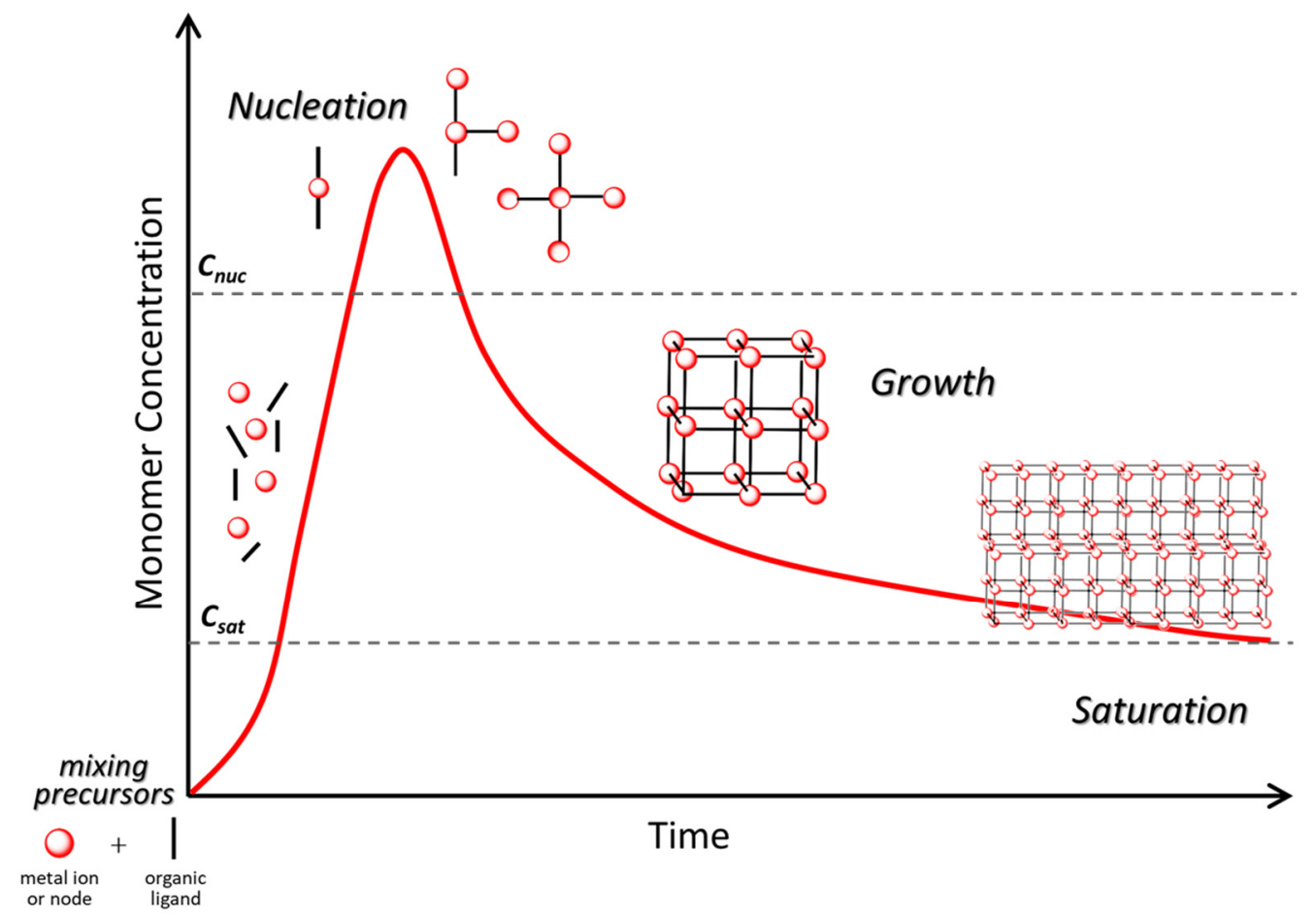

Figure 9. Scheme of the LaMer model to explain the evolution of MOF crystals through nucleation and growth.

MOF's crystalline particles can be synthesized at different scales; from macro- to micro- and nano-scale. When reduced to the nanoregime, MOF nanocrystals (i.e., nanoscale MOFs, or nano-MOFs) can offer significantly enhanced properties compared to their bulk counterparts, such as controllable diffusion kinetics, high ratio of exposed active sites, and efficient confinement of redox centers. The possibility of having nano-MOFs has allowed novel applications where a specific size is required, as is the case of biomedical applications [131] and nanocatalysis [132]. MOF nanoparticles can also serve as basic building blocks for the assembly of superstructures with complicated morphologies, that is, hierarchical assemblies [133]. There are several synthetic methods for scaling down the MOFs to the nanoscale [134,135], which can be included in one of the two following approaches: (i) placement of metal ions and organic linkers in confined spaces by using emulsions, templates, or surfactants to confine the MOF formation within the nanospace, restricting the crystal growth and thus leading to smaller MOF sizes; or (ii) promotion of nucleation over crystal growth, for example by tuning the reactants concentration or introducing modulators. Alternatively, the use of microwave and ultrasound synthesis are also strategies to accelerate the nucleation stage of MOFs. However, obtaining uniform nanoscale MOF particles is not a simple task, and it has not yet been achieved for some MOF types. During a typical MOF synthesis, it is common to obtain a mixture of particles with various sizes and/or morphologies (i.e., low homogeneity), which makes it difficult to control the properties of the material on a large scale. Furthermore, given the difficulty of purifying MOF nanoparticles post-synthetically, the optimization of synthetic methods with a high control on the size and monodispersity of nano-MOFs is of great importance. As an example of the control of the MOF crystal size, the zeolitic imidazolate framework-8 (ZIF-8) can be synthesized with different particle sizes (from few nanometers to micrometers) by adjusting the concentration of a surfactant, specifically CTAB, that acts as a growth inhibitor (Figure 10A) [136]. Likewise, the reactivity of the $\mathrm{Zn}^{2+}$ salt used as a precursor also has a strong influence on the size of the ZIF-8 particles, and varying the kinetic of the nucleation stage is also a common strategy to tune the MOF size [137]. Note that, regardless 
of the size or morphology of the ZIF-8 crystals, all of them present identical crystallinity, with a sodalite-type structure. However, changes in the particle size induce changes in stability and adsorption properties, as has been demonstrated through thermogravimetric analysis and Brunauer-Emmett-Teller (BET) surface area measurements. As a general trend, smaller MOF crystals exhibit higher surface areas and better catalytic activities, but lower stability.

A

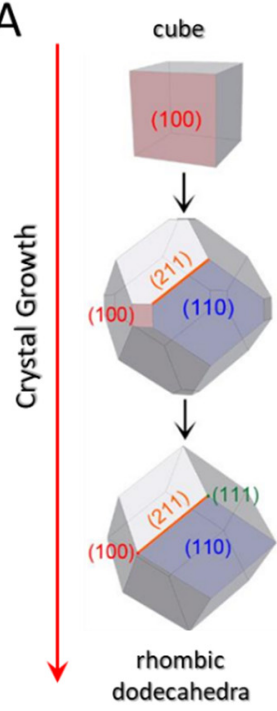

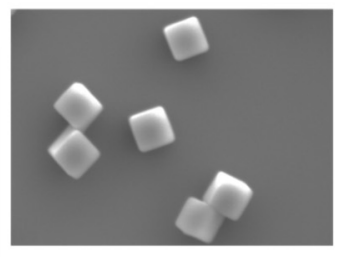

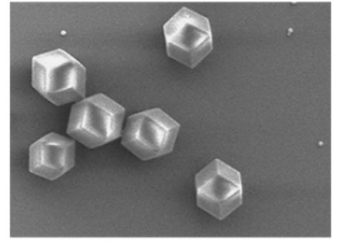

B

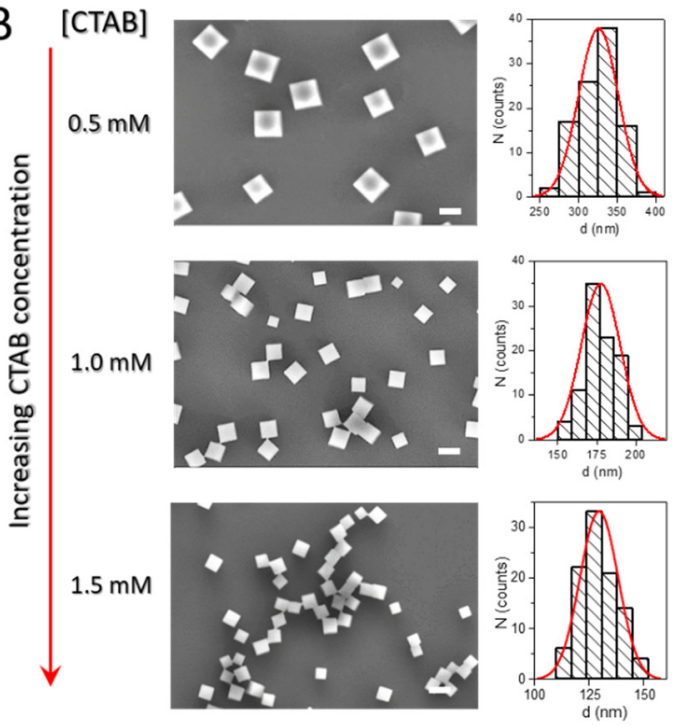

Figure 10. (A) Morphological evolution of ZIF-8 crystals synthesized without modulators or capping agents. (B) Effect of the addition of surfactant CTAB as a modulator in the ZIF-8 synthesis; higher CTAB concentration leads to smaller crystal size. Scale bars in SEM images correspond to $200 \mathrm{~nm}$.

Apart of the control of the size, synthesizing MOFs with specific morphologies is also challenging. In principle, the final shape of a MOF particle is the consequence of the Wulff's rule, where the slowest growing direction thermodynamically determines the final shape and the most stable facet orientation [136]. However, there are strategies to favor the crystal growth towards preferred orientations, and thus achieve a controllable growth of specific crystal faces. By adjusting the reaction conditions and/or by introducing growthblocking agents that inhibit a specific growth direction, the shape of the MOF particles can be tuned to nanospheres, nanocubes, nanorods, and nanoplates. As an example, HKUST-1 can be selectively formed in different geometries (cube, cuboctahedron, and octahedron) by using modulators. Kitagawa and coworkers systematically investigated the effects of n-dodecanoic acid as a growth-blocking agent, which decelerates the crystal growth in the $<100>$ direction and favors the $<111>$ direction, leading to preferential formation of the cubic morphology [138]. In the case of ZIF-8, the crystal growth of a particle starts from an all $<100>$ oriented cube that gradually evolves first into truncated rhombic dodecahedral shape and finally to rhombic dodecahedral shape, in which all the facets are $<110>$ oriented (Figure 10A). The addition of the surfactant CTAB in the ZIF-8 synthesis has an effect on the size of the crystal particles, as stated above, but it also works as a modulator of the particle shape [136]. Increasing the CTAB concentration suppresses the $<100>$ growth of ZIF-8, leading to the formation of smaller and cubic-shaped crystals (Figure 10B). This is due to the selective attachment of the hydrophobic tail of the CTAB molecules on the energetically favorable $<100>$ facets.

Taking a step further, post-synthetic bottom-up strategies have been used to obtain new morphologies or complex core-shell structures (MOF1@MOF2). Generally, these strategies consist of synthesizing the first $\mathrm{MOF}$ as a core followed with the growth of the second MOF on the pre-synthesized core particles. One of the first examples in this direction was reported by Matzger and coworkers in 2009, where IRMOF-3 was grown 
over cubic-shaped MOF-5 and vice versa [139]. They also demonstrated the possibility of growing a second MOF layer, yielding three-layered crystals made of two different MOFs in a Matryoshka doll-like or onion-like design (Figure 11A). Similarly, Yamauchi and coworkers used the same strategy to produce core-shell ZIF-8@ZIF-67 particles, and investigated their transformation into porous carbon materials by pyrolysis maintaining the rhombic dodecahedral shape in both the core and shell [140]. Under the same pyrolysis conditions $\left(800{ }^{\circ} \mathrm{C}\right.$ in $\mathrm{N}_{2}$ atmosphere for $3 \mathrm{~h}$ ), the ZIF- 8 was transformed into highly porous $\mathrm{N}$-doped amorphous carbon (NC), whereas the ZIF-67 exhibited less porous but crystalline graphitic carbon (GC), Figure 11B. This NC@GC material presented good electrocatalytic activity for oxygen reduction reactions.

A (a)

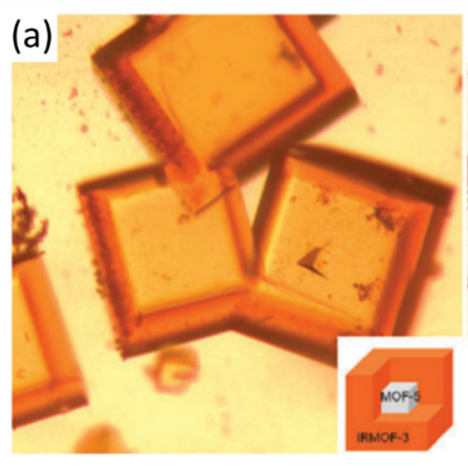

(b)

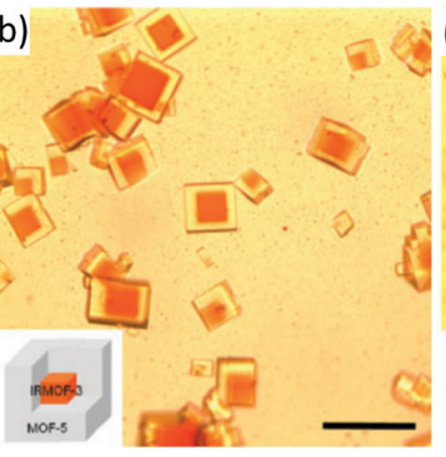

(c)

B

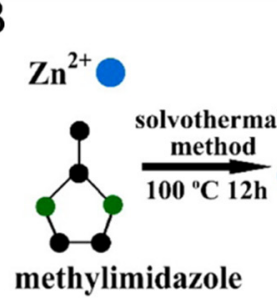

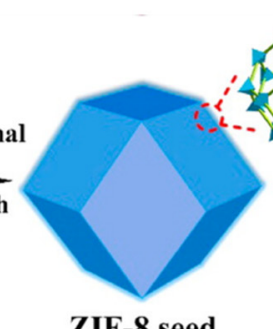

ZIF-8 seed

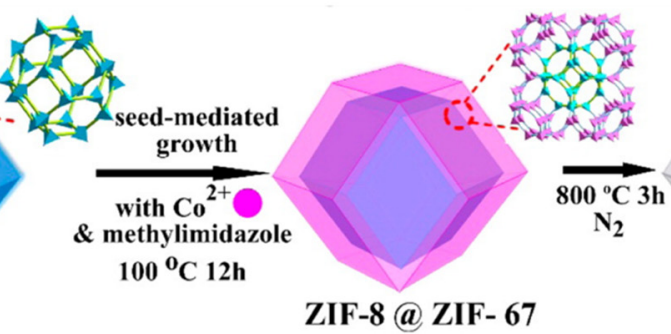

ZIF-8@ZIF-67

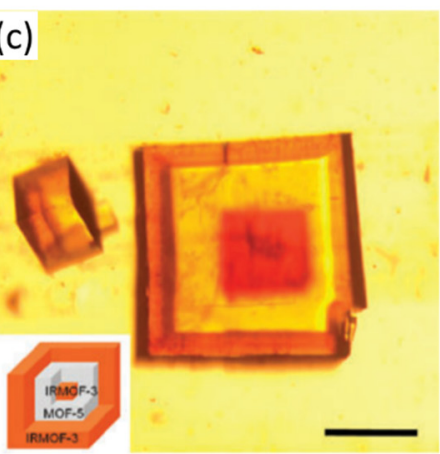

inMor.s

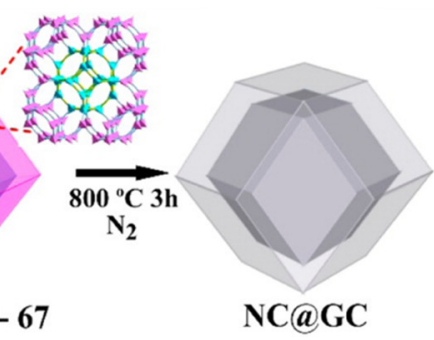

Figure 11. (A) Microscope images of core-shell MOFs (a) MOF-5@IRMOF-3, (b) IRMOF-3@MOF-5, and (c) Matryoshka doll-like IRMOF-3@MOF-5@IRMOF-3 particles. Scale bars corresponds to $200 \mathrm{~mm}$. Reproduced with permission of [139]. Copyright the Royal Society of Chemistry, 2009. (B) Synthetic scheme for the preparation of core-shell ZIF-8@ZIF-67 crystals and NC@GC. Reproduced with permission of [140]. Copyright the American Chemical Society, 2015.

In addition to the above discussed synthetic strategies which rely on a bottom-up approach, there is also top-down approach, for example by exfoliation of large MOF crystals through ultrasonication, ball milling, and grinding. However, these top-down methods are much less applicable because of their intrinsic limitations, mainly the lack of precise control over the size and morphology of the obtained particles (samples with a high heterogeneity) and reproducibility issues. On the other hand, one interesting example reported by Maspoch and coworkers is the possibility of selectively changing the morphology of ZIFs (ZIF-8 and ZIF-67 nanocrystals) by an anisotropic wet-chemical etching strategy [141]. That is a top-down approach that controllably deconstructs the material to yield unprecedentedly shaped, hierarchically porous, or simply hollow crystals. They could demonstrate that (i) the etching occurs preferentially in the crystallographic directions richer in metal-ligand bonds; (ii) the etching rate tends to be faster on the crystal surfaces of higher dimensionality; and (iii) the $\mathrm{pH}$ of the etchant solution is the key to modulate the etching process.

In addition, to obtain structure-controllable synthetic routes, the synthesis of MOFs is rapidly evolving to be easier, faster, greener, and to obtain higher yields and scalingup methods with the consequent cost reduction (especially relevant from an industrial point of view). In this direction, microwave-assisted, sonochemical, mechanochemical, 
microfluidic, and continuous flow syntheses of MOFs are the most promising synthetic methods [142]. Compared to conventional heating techniques, the microwave-assisted method permits shorter heating durations (only a few minutes) due to the application of more concentrated and localized power, which results in increased nucleation and thus smaller particle sizes [143]. Likewise, ultrasound-assisted synthesis provides a localized high temperature and pressure generated by acoustic cavitation, which leads to enhanced nucleation, controlled particle morphology, and phase selectivity [143]. However, to date, microwave- and ultrasound-assisted methods are only applicable for a limited number of MOFs. The synthesis of MOFs by mecanochemistry implies the use of mechanical grinding (mechanical force) to provide the necessary energy and promote the reaction for the MOF formation [144]. Mechanochemical methods are solvent-free, which make them a convenient green and scalable alternative to prepare MOFs. Nevertheless, a high control of size and shape of the obtained crystals is quite difficult to achieve, and irreproducibility is the major drawback of mecanochemical synthetic routes. Continuous flow process for the synthesis of MOFs would scale up and improve the efficiency [145]. However, there are still important limitations and challenges to obtain MOFs with optimum properties, and, to date, there are only a few examples of successful synthesis for some MOF types. The concerted effort of chemists and engineers is key of success in this direction, and a lot of recent work is being focused on this goal.

\section{Evolution and Perspectives}

Although the number of protocols for the synthesis of uniform nanostructures has grown exponentially in the two last decades, there are still many challenges that currently demand the effort and the attention of chemists. Firstly, nanostructuration strategies should be extended to many more systems. This includes silicate, aluminate, and other refractory materials. The traditional synthesis of such materials often requires elevated temperatures, resulting in many cases in heterogeneous microparticles. Synthetic routes at milder conditions that provide a control on the particle morphologies for many material compositions are still demanded. Moreover, the design of synthetic protocols yielding more complex and hierarchical nanostructures, with the integration of different structures and functionalities in a same nanosystem, is another topic to better develop. Examples are core-shell nanoparticles, Matryoshka doll-like nanoparticles, and Janus nanoparticles.

The lack of routes for the synthesis of large amounts of inorganic and hybrid organicinorganic nanomaterials is one limiting factor, given that, in most cases, it hinders the transfer of nanostructures from the laboratory to the market and industry. The effect of higher precursor concentrations, and different reactor geometries and volumes on the particle morphology and homogeneity when compared to the laboratory scale, is yet to be studied and optimized. The design of protocols for the large-scale and cost-effective synthesis of nanoparticles, including faster and easier purification strategies, is thus one important current challenge.

As a general trend, alternative protocols to promote green synthesis are also highly desirable. This includes the use of chemicals with reduced toxicity and the design of reactions demanding milder synthetic conditions. Green chemistry protocols and biomimetic synthesis are some examples of the evolution within this topic.

Regarding syntheses based on polymerization and condensation, the development of a non-aqueous sol-gel chemistry is one of the possible evolutions of the sol-gel synthesis of nanomaterials. Given that the production of water is involved in the hydrolysis and condensation of metal alkoxides, the kinetics of the reactions is strongly dependent on water content. The design of non-aqueous condensation reactions may offer enhanced control on the kinetics, which may lead to a more controlled morphology of the nanostructures [146]. Examples of non-hydrolytic sol-gel chemistry include alkyl halide elimination, ether elimination, ester elimination, and aldol-like condensation [147]. Focusing on porous materials for catalysis, structures with abundant exposed active sites and highly accessible surfaces are also desirable. 
Extensive efforts have already been devoted to developing efficient synthetic bottomup strategies for obtaining MOFs with controllable sizes and morphologies. However, this field of research is still in its infancy and there are still many challenges for further investigations. On the one hand, one important challenge is large-scale synthesis of MOFs due to the following reasons: high price of ligands for some MOFs, harsh synthetic conditions for diverse MOFs, low yields of most of the synthetic methods, and limited control of the structure and properties, among others. On the other hand, applications of conventional microporous MOFs are usually hampered by their limited pore sizes, especially in the fields of heterogeneous catalysis and cargo delivery, where large molecules have diffusion limitations. Therefore, the development of strategies to construct hierarchically porous MOFs, containing mesopores $(2-50 \mathrm{~nm})$ or even macropores $(>50 \mathrm{~nm})$ in addition to micropores $(<2 \mathrm{~nm})$, is of utmost importance. Moreover, benefiting from the knowledge gained from the MOF synthetic chemistry to date, much research is focused on the assembly of MOF nanostructures with uniform sizes and shapes into hierarchical superstructures, which can be used to construct electronic and photonic nanodevices. The functionalization and optimization of the surface reactions in hybrid systems to change, improve, or modify the properties of the nanostructures, thus affecting their colloidal stability, is another important point to consider. This demands a closer collaboration between both inorganic and organic chemists.

Last but not least, perhaps one of the major difficulties found in the laboratories of chemistry is the reproducibility. Although this is in fact a complex issue, given that many different parameters and variables can affect the chemical reactions, including the role played by impurities [148], some good practices might help. For example, full details of the reaction scheme, including in many cases "tricks" and the complete references of the used chemical reagents, could be given when reporting synthesis protocols of nanostructures.

Author Contributions: Writing-original draft, A.E. and C.C.-C.; Writing-review \& editing, A.E., C.C.-C., E.R.-B., A.F., C.R.-B., M.C.C. and N.K. Funding acquisition, A.E., C.C.-C. and N.K. All authors have read and agreed to the published version of the manuscript.

Funding: Authors want to thank the sixth Research and Technology Transfer Plan of the University of Seville (VI PPIT-US, to A.E.), and the projects CTQ2016-78580-C2-1-R of the Spanish Ministry of Economy and Competitiveness, COST action CA-18132 "Functional Glyconanomaterials for the Development of Diagnostic and Targeted Therapeutic Probe", and CSIC PIE 202080E157 (to N.K.). C.C.-C. acknowledges the financial support of the Spanish MINECO through Project No. PID2019107665RJ-I00, and the Spanish Ministry of Science and Innovation for financial support under the Ramón y Cajal Program (RYC2019-027527-I). A.F. gratefully acknowledges MINECO for the provision of a FPI contract (BES-2017-081560) associated with the CTQ2016-78289-P project.

Institutional Review Board Statement: Not applicable.

Informed Consent Statement: Not applicable.

Data Availability Statement: Not applicable.

Conflicts of Interest: The authors declare no conflict of interest.

\section{References}

1. Weller, M.; Overton, T.; Rourke, J.; Armstrong, F. Inorganic Chemistry, 7th ed.; Oxford University Press: Oxford, UK, 2018.

2. Bera, D.; Qian, L.; Tseng, T.-K.; Holloway, P.H. Quantum Dots and Their Multimodal Applications: A Review. Materials 2010, 3, 2260-2345. [CrossRef]

3. Zhou, Y.; Zhao, H.; Ma, D.; Rosei, F. Harnessing the properties of colloidal quantum dots in luminescent solar concentrators. Chem. Soc. Rev. 2018, 47, 5866-5890. [CrossRef]

4. Argudo, P.G.; Carril, M.; Martín-Romero, M.T.; Giner-Casares, J.J.; Carrillo-Carrión, C. Surface-Active Fluorinated Quantum Dots for Enhanced Cellular Uptake. Chem. Eur. J. 2019, 25, 195-199. [CrossRef]

5. Cayuela, A.; Soriano, M.L.; Carrillo-Carrión, C.; Valcárcel, M. Semiconductor and carbon-based fluorescent nanodots: The need for consistency. Chem. Commun. 2016, 52, 1311-1326. [CrossRef] [PubMed]

6. Bonatti, L.; Gil, G.; Giovannini, T.; Corni, S.; Cappelli, C. Plasmonic Resonances of Metal Nanoparticles: Atomistic vs. Continuum Approaches. Front. Chem. 2020, 8, 340. [CrossRef] 
7. Sundaresan, A.; Rao, C.N.R. Ferromagnetism as a universal feature of inorganic nanoparticles. Nano Today 2009, 4, 96-106. [CrossRef]

8. Hötzer, B.; Medintz, I.L.; Hildebrandt, N. Fluorescence in Nanobiotechnology: Sophisticated Fluorophores for Novel Applications. Small 2012, 8, 2297-2326. [CrossRef]

9. Taeho, K.; Taeghwan, H. Applications of inorganic nanoparticles as therapeutic agents. Nanotechnology 2014, $25,012001$.

10. Pelaz, B.; Alexiou, C.; Alvarez-Puebla, R.A.; Alves, F.; Andrews, A.M.; Ashraf, S.; Balogh, L.P.; Ballerini, L.; Bestetti, A.; Brendel, C.; et al. Diverse Applications of Nanomedicine. ACS Nano 2017, 11, 2313-2381. [CrossRef]

11. Escudero, A.; Carrillo-Carrión, C.; Castillejos, M.C.; Romero-Ben, E.; Rosales-Barrios, C.; Khiar, N. Photodynamic therapy: Photosensitizers and nanostructures. Mat. Chem. Front. 2021, 5, 3788-3812. [CrossRef]

12. Martín-Palma, R.J.; Martínez-Duart, J.M. Nanotechnology for Microelectronics and Photonics; Elsevier: Amsterdam, The Netherlands, 2017.

13. Naseem, F.; Lu, P.; Zeng, J.; Lu, Z.; Ng, Y.H.; Zhao, H.; Du, Y.; Yin, Z. Solid Nanoporosity Governs Catalytic $\mathrm{CO}_{2}$ and $\mathrm{N}_{2}$ Reduction. ACS Nano 2020, 14, 7734-7759. [CrossRef]

14. Yang, D.; Zhu, Q.; Chen, C.; Liu, H.; Liu, Z.; Zhao, Z.; Zhang, X.; Liu, S.; Han, B. Selective electroreduction of carbon dioxide to methanol on copper selenide nanocatalysts. Nat. Commun. 2019, 10, 677. [CrossRef] [PubMed]

15. Liu, Q.; Yang, X.; Li, L.; Miao, S.; Li, Y.; Li, Y.; Wang, X.; Huang, Y.; Zhang, T. Direct catalytic hydrogenation of $\mathrm{CO}_{2}$ to formate over a Schiff-base-mediated gold nanocatalyst. Nat. Commun. 2017, 8, 1407. [CrossRef] [PubMed]

16. Wei, J.; Ge, Q.; Yao, R.; Wen, Z.; Fang, C.; Guo, L.; Xu, H.; Sun, J. Directly converting $\mathrm{CO}_{2}$ into a gasoline fuel. Nat. Commun. 2017, 8, 15174. [CrossRef] [PubMed]

17. Sim, H.Y.F.; Chen, J.R.T.; Koh, C.S.L.; Lee, H.K.; Han, X.; Phan-Quang, G.C.; Pang, J.Y.; Lay, C.L.; Pedireddy, S.; Phang, I.Y.; et al. ZIF-Induced d-Band Modification in a Bimetallic Nanocatalyst: Achieving Over $44 \%$ Efficiency in the Ambient Nitrogen Reduction Reaction. Angew. Chem. Int. Edit. 2020, 59, 16997-17003. [CrossRef]

18. Wu, C.H.; Liu, C.; Su, D.; Xin, H.L.; Fang, H.-T.; Eren, B.; Zhang, S.; Murray, C.B.; Salmeron, M.B. Bimetallic synergy in cobalt-palladium nanocatalysts for CO oxidation. Nat. Catal. 2019, 2, 78-85. [CrossRef]

19. Lu, F.; Astruc, D. Nanocatalysts and other nanomaterials for water remediation from organic pollutants. Coord. Chem. Rev. 2020, 408, 213180. [CrossRef]

20. Fu, S.; Song, J.; Zhu, C.; Xu, G.-L.; Amine, K.; Sun, C.; Li, X.; Engelhard, M.H.; Du, D.; Lin, Y. Ultrafine and highly disordered Ni2Fe1 nanofoams enabled highly efficient oxygen evolution reaction in alkaline electrolyte. Nano Energy 2018, 44, 319-326. [CrossRef]

21. Müller, U. (Ed.) Nanostructures. In Inorganic Structural Chemistry; John WIlley \& Sons: West Sussex, UK, 2006 ; pp. $241-245$.

22. Bellah, M.M.; Christensen, S.M.; Iqbal, S.M. Nanostructures for Medical Diagnostics. J. Nanomater. 2012, 2012, 486301. [CrossRef]

23. Baláž, P.; Achimovičová, M.; Baláž, M.; Billik, P.; Cherkezova-Zheleva, Z.; Criado, J.M.; Delogu, F.; Dutková, E.; Gaffet, E.; Gotor, F.J.; et al. Hallmarks of mechanochemistry: From nanoparticles to technology. Chem. Soc. Rev. 2013, 42, 7571-7637. [CrossRef] [PubMed]

24. Parvez Iqbal, J.A.P.; Mendes, P.M. Nanotechnology: The “Top-Down" and "Bottom-Up" Approaches. In Supramolecular Chemistry: From Molecules to Nanomaterials; Gale, P.A., Ed.; John Wiley \& Sons: Hoboken, NJ, USA, 2012.

25. Lehn, J.-M. Supramolecular Chemistry—Scope and Perspectives Molecules, Supermolecules, and Molecular Devices (Nobel Lecture). Angew. Chem. Int. Ed. Engl. 1988, 27, 89-112. [CrossRef]

26. Balzani, V. Nanoscience and Nanotechnology: A Personal View of a Chemist. Small 2005, 1, 278-283. [CrossRef]

27. Pu, Y.; Cai, F.; Wang, D.; Wang, J.-X.; Chen, J.-F. Colloidal Synthesis of Semiconductor Quantum Dots toward Large-Scale Production: A Review. Ind. Eng. Chem. Res. 2018, 57, 1790-1802. [CrossRef]

28. Nikam, A.V.; Prasad, B.L.V.; Kulkarni, A.A. Wet chemical synthesis of metal oxide nanoparticles: A review. CrystEngComm 2018, 20, 5091-5107. [CrossRef]

29. Hühn, J.; Carrillo-Carrion, C.; Soliman, M.G.; Pfeiffer, C.; Valdeperez, D.; Masood, A.; Chakraborty, I.; Zhu, L.; Gallego, M.; Yue, Z.; et al. Selected Standard Protocols for the Synthesis, Phase Transfer, and Characterization of Inorganic Colloidal Nanoparticles. Chem. Mat. 2017, 29, 399-461. [CrossRef]

30. Esposito, S. "Traditional" Sol-Gel Chemistry as a Powerful Tool for the Preparation of Supported Metal and Metal Oxide Catalysts. Materials 2019, 12, 668. [CrossRef]

31. Tranquillo, E.; Barrino, F.; Dal Poggetto, G.; Blanco, I. Sol-Gel Synthesis of Silica-Based Materials with Different Percentages of PEG or PCL and High Chlorogenic Acid Content. Materials 2019, 12, 155. [CrossRef]

32. Schubert, U. 7.10-Sol-Gel Processing of Metal Compounds. In Comprehensive Coordination Chemistry II; McCleverty, J.A., Meyer, T.J., Eds.; Elsevier: Amsterdam, The Netherlands, 2003; pp. 629-656.

33. Pekala, R.W. Organic aerogels from the polycondensation of resorcinol with formaldehyde. J. Mater. Sci. 1989, 24, 3221-3227. [CrossRef]

34. Parashar, M.; Shukla, V.K.; Singh, R. Metal oxides nanoparticles via sol-gel method: A review on synthesis, characterization and applications. J. Mater. Sci. Mater. Electron. 2020, 31, 3729-3749. [CrossRef]

35. Feinle, A.; Elsaesser, M.S.; Hüsing, N. Sol-gel synthesis of monolithic materials with hierarchical porosity. Chem. Soc. Rev. 2016, 45,3377-3399. [CrossRef] 
36. Cushing, B.L.; Kolesnichenko, V.L.; O'Connor, C.J. Recent Advances in the Liquid-Phase Syntheses of Inorganic Nanoparticles. Chem. Rev. 2004, 104, 3893-3946. [CrossRef] [PubMed]

37. Jiang, X.; Wang, Y.; Herricks, T.; Xia, Y. Ethylene glycol-mediated synthesis of metal oxide nanowires. J. Mater. Chem. 2004, 14, 695-703. [CrossRef]

38. Li, G.; Zhang, S.; Yu, J. Facile Synthesis of Single-Phase $\mathrm{TiO}_{2}$ Nanocrystals with High Photocatalytic Performance. J. Am. Ceram. Soc. 2011, 94, 4112-4115. [CrossRef]

39. Nakanishi, K.; Tanaka, N. Sol-Gel with Phase Separation. Hierarchically Porous Materials Optimized for High-Performance Liquid Chromatography Separations. Acc. Chem. Res. 2007, 40, 863-873. [CrossRef]

40. Galarneau, A.; Abid, Z.; Said, B.; Didi, Y.; Szymanska, K.; Jarzębski, A.; Tancret, F.; Hamaizi, H.; Bengueddach, A.; Di Renzo, F.; et al. Synthesis and Textural Characterization of Mesoporous and Meso-/Macroporous Silica Monoliths Obtained by Spinodal Decomposition. Inorganics 2016, 4, 9. [CrossRef]

41. Konishi, J.; Fujita, K.; Nakanishi, K.; Hirao, K. Monolithic $\mathrm{TiO}_{2}$ with Controlled Multiscale Porosity via a Template-Free Sol-Gel Process Accompanied by Phase Separation. Chem. Mat. 2006, 18, 6069-6074. [CrossRef]

42. Ackermann, S.; Steinfeld, A. Spectral hemispherical reflectivity of nonstoichiometric cerium dioxide. Sol. Energy Mater. Sol. Cells 2017, 159, 167-171. [CrossRef]

43. Manzano, M.; Vallet-Regí, M. Mesoporous Silica Nanoparticles for Drug Delivery. Adv. Funct. Mater. 2020, 30, 1902634. [CrossRef]

44. Narayan, R.; Nayak, U.Y.; Raichur, A.M.; Garg, S. Mesoporous Silica Nanoparticles: A Comprehensive Review on Synthesis and Recent Advances. Pharmaceutics 2018, 10, 118. [CrossRef]

45. Gisbert-Garzarán, M.; Vallet-Regí, M. Influence of the Surface Functionalization on the Fate and Performance of Mesoporous Silica Nanoparticles. Nanomaterials 2020, 10, 916. [CrossRef] [PubMed]

46. Anwander, R.; Palm, C.; Stelzer, J.; Groeger, O.; Engelhardt, G. Silazane-silylation of mesoporous silicates: Towards tailor-made support materials. In Studies in Surface Science and Catalysis; Bonneviot, L., Béland, F., Danumah, C., Giasson, S., Kaliaguine, S., Eds.; Elsevier: Amsterdam, The Netherlands, 1998; Volume 117, pp. 135-142.

47. Kolb, H.C.; Finn, M.G.; Sharpless, K.B. Click Chemistry: Diverse Chemical Function from a Few Good Reactions. Angew. Chem. Int. Edit. 2001, 40, 2004-2021. [CrossRef]

48. Wang, T.; Gao, L.; Hou, J.; Herou, S.J.A.; Griffiths, J.T.; Li, W.; Dong, J.; Gao, S.; Titirici, M.-M.; Kumar, R.V.; et al. Rational approach to guest confinement inside MOF cavities for low-temperature catalysis. Nat. Commun. 2019, 10, 1340. [CrossRef]

49. Ebadi Amooghin, A.; Sanaeepur, H.; Omidkhah, M.; Kargari, A. "Ship-in-a-bottle", a new synthesis strategy for preparing novel hybrid host-guest nanocomposites for highly selective membrane gas separation. J. Mater. Chem. A 2018, 6, 1751-1771. [CrossRef]

50. Yu, Y.; Mai, J.; Wang, L.; Li, X.; Jiang, Z.; Wang, F. Ship-in-a-bottle synthesis of amine-functionalized ionic liquids in NaY zeolite for $\mathrm{CO}_{2}$ capture. Sci. Rep. 2014, 4, 5997. [CrossRef]

51. Alkordi, M.H.; Liu, Y.; Larsen, R.W.; Eubank, J.F.; Eddaoudi, M. Zeolite-like Metal-Organic Frameworks as Platforms for Applications: On Metalloporphyrin-Based Catalysts. J. Am. Chem. Soc. 2008, 130, 12639-12641. [CrossRef] [PubMed]

52. Juan-Alcañiz, J.; Gascon, J.; Kapteijn, F. Metal-organic frameworks as scaffolds for the encapsulation of active species: State of the art and future perspectives. J. Mater. Chem. 2012, 22, 10102-10118. [CrossRef]

53. Zhan, B.-Z.; Li, X.-Y. A novel 'build-bottle-around-ship' method to encapsulate metalloporphyrins in zeolite-Y. An efficient biomimetic catalyst. Chem. Commun. 1998, 349-350. [CrossRef]

54. Sun, C.; Zhang, F.; Cao, J. A 'build-bottle-around-ship' method to encapsulate ammonium molybdophosphate in zeolite Y. An efficient adsorbent for cesium. J. Colloid Interface Sci. 2015, 455, 39-45. [CrossRef]

55. Nakazawa, J.; Smith, B.J.; Stack, T.D.P. Discrete Complexes Immobilized onto Click-SBA-15 Silica: Controllable Loadings and the Impact of Surface Coverage on Catalysis. J. Am. Chem. Soc. 2012, 134, 2750-2759. [CrossRef]

56. Han, Y.R.; Park, J.-W.; Kim, H.; Ji, H.; Lim, S.H.; Jun, C.-H. A one-step co-condensation method for the synthesis of well-defined functionalized mesoporous SBA-15 using trimethallylsilanes as organosilane sources. Chem. Commun. 2015, 51, 17084-17087. [CrossRef]

57. Zyuzin, M.V.; Zhu, D.; Parak, W.J.; Feliu, N.; Escudero, A. Development of Silica-Based Biodegradable Submicrometric Carriers and Investigating Their Characteristics as in Vitro Delivery Vehicles. Int. J. Mol. Sci. 2020, 21, 7563. [CrossRef]

58. Ott, A.; Yu, X.; Hartmann, R.; Rejman, J.; Schütz, A.; Ochs, M.; Parak, W.J.; Carregal-Romero, S. Light-Addressable and Degradable Silica Capsules for Delivery of Molecular Cargo to the Cytosol of Cells. Chem. Mat. 2015, 27, 1929-1942. [CrossRef]

59. El Kadib, A.; Bousmina, M. Chitosan Bio-Based Organic-Inorganic Hybrid Aerogel Microspheres. Chem. Eur. J. 2012, 18, 8264-8277. [CrossRef]

60. El Kadib, A. Green and Functional Aerogels by Macromolecular and Textural Engineering of Chitosan Microspheres. Chem. Rec. 2020, 20, 753-772. [CrossRef]

61. Rudisill, S.G.; Shaker, S.; Terzic, D.; Le Maire, R.; Su, B.-L.; Stein, A. Generalized Approach to the Microstructure Direction in Metal Oxide Ceramics via Polymerization-Induced Phase Separation. Inorg. Chem. 2015, 54, 993-1002. [CrossRef] [PubMed]

62. Groeneveld, E.; de Mello Donegá, C. The Challenge of Colloidal Nanoparticle Synthesis. In Nanoparticles: Workhorses of Nanoscience; de Mello Donegá, C., Ed.; Springer: Berlin/Heidelberg, Germany, 2014; pp. 145-189.

63. Lee, K.J.; Yoon, J.; Lahann, J. Recent advances with anisotropic particles. Curr. Opin. Colloid Interface Sci. 2011, 16, 195-202. [CrossRef] 
64. Wichaita, W.; Polpanich, D.; Tangboriboonrat, P. Review on Synthesis of Colloidal Hollow Particles and Their Applications. Ind. Eng. Chem. Res. 2019, 58, 20880-20901. [CrossRef]

65. Ghosh Chaudhuri, R.; Paria, S. Core/Shell Nanoparticles: Classes, Properties, Synthesis Mechanisms, Characterization, and Applications. Chem. Rev. 2012, 112, 2373-2433. [CrossRef]

66. Walther, A.; Müller, A.H.E. Janus Particles: Synthesis, Self-Assembly, Physical Properties, and Applications. Chem. Rev. 2013, 113, 5194-5261. [CrossRef] [PubMed]

67. Atkins, P.; De Paula, J.; Keeler, J. Physical Chemistry, 11th ed.; Oxford University Press: Oxford, UK, 2017.

68. Guerrini, L.; Alvarez-Puebla, R.A.; Pazos-Perez, N. Surface Modifications of Nanoparticles for Stability in Biological Fluids. Materials 2018, 11, 1154. [CrossRef]

69. LaMer, V.K.; Dinegar, R.H. Theory, Production and Mechanism of Formation of Monodispersed Hydrosols. J. Am. Chem. Soc. 1950, 72, 4847-4854. [CrossRef]

70. Heuer-Jungemann, A.; Feliu, N.; Bakaimi, I.; Hamaly, M.; Alkilany, A.; Chakraborty, I.; Masood, A.; Casula, M.F.; Kostopoulou, A.; Oh, E.; et al. The Role of Ligands in the Chemical Synthesis and Applications of Inorganic Nanoparticles. Chem. Rev. 2019, 119, 4819-4880. [CrossRef]

71. Ashraf, S.; Pelaz, B.; del Pino, P.; Carril, M.; Escudero, A.; Parak, W.J.; Soliman, M.G.; Zhang, Q.; Carrillo-Carrion, C. Gold-Based Nanomaterials for Applications in Nanomedicine. In Light-Responsive Nanostructured Systems for Applications in Nanomedicine; Sortino, S., Ed.; Springer International Publishing: Cham, Switzerland, 2016; pp. 169-202.

72. Niu, W.; Zhang, L.; Xu, G. Seed-mediated growth of noble metal nanocrystals: Crystal growth and shape control. Nanoscale 2013, 5, 3172-3181. [CrossRef]

73. Murphy, C.J.; Thompson, L.B.; Chernak, D.J.; Yang, J.A.; Sivapalan, S.T.; Boulos, S.P.; Huang, J.; Alkilany, A.M.; Sisco, P.N. Gold nanorod crystal growth: From seed-mediated synthesis to nanoscale sculpting. Curr. Opin. Colloid Interface Sci. 2011, 16, 128-134. [CrossRef]

74. Polavarapu, L.; Mourdikoudis, S.; Pastoriza-Santos, I.; Pérez-Juste, J. Nanocrystal engineering of noble metals and metal chalcogenides: Controlling the morphology, composition and crystallinity. CrystEngComm 2015, 17, 3727-3762. [CrossRef]

75. Bastús, N.G.; Comenge, J.; Puntes, V. Kinetically Controlled Seeded Growth Synthesis of Citrate-Stabilized Gold Nanoparticles of up to $200 \mathrm{~nm}$ : Size Focusing versus Ostwald Ripening. Langmuir 2011, 27, 11098-11105. [CrossRef]

76. Ye, X.; Zheng, C.; Chen, J.; Gao, Y.; Murray, C.B. Using Binary Surfactant Mixtures To Simultaneously Improve the Dimensional Tunability and Monodispersity in the Seeded Growth of Gold Nanorods. Nano Lett. 2013, 13, 765-771. [CrossRef]

77. Liz-Marzán, L.M. Gold nanoparticle research before and after the Brust-Schiffrin method. Chem. Commun. 2013, 49, 16-18. [CrossRef] [PubMed]

78. Murphy, C.J.; Thompson, L.B.; Alkilany, A.M.; Sisco, P.N.; Boulos, S.P.; Sivapalan, S.T.; Yang, J.A.; Chernak, D.J.; Huang, J. The Many Faces of Gold Nanorods. J. Phys. Chem. Lett. 2010, 1, 2867-2875. [CrossRef]

79. Xia, X.; Zeng, J.; Oetjen, L.K.; Li, Q.; Xia, Y. Quantitative Analysis of the Role Played by Poly(vinylpyrrolidone) in Seed-Mediated Growth of Ag Nanocrystals. J. Am. Chem. Soc. 2012, 134, 1793-1801. [CrossRef]

80. Loiseau, A.; Asila, V.; Boitel-Aullen, G.; Lam, M.; Salmain, M.; Boujday, S. Silver-Based Plasmonic Nanoparticles for and Their Use in Biosensing. Biosensors 2019, 9, 78. [CrossRef] [PubMed]

81. Matijevic, E. Preparation and properties of uniform size colloids. Chem. Mat. 1993, 5, 412-426. [CrossRef]

82. Amiens, C.; Chaudret, B.; Ciuculescu-Pradines, D.; Collière, V.; Fajerwerg, K.; Fau, P.; Kahn, M.; Maisonnat, A.; Soulantica, K.; Philippot, K. Organometallic approach for the synthesis of nanostructures. New J. Chem. 2013, 37, 3374-3401. [CrossRef]

83. Moraes, L.C.; Figueiredo, R.C.; Espinós, J.P.; Vattier, F.; Franconetti, A.; Jaime, C.; Lacroix, B.; Rojo, J.; Lara, P.; Conejero, S. Platinum nanoparticles stabilized by N-heterocyclic thiones. Synthesis and catalytic activity in mono- and di-hydroboration of alkynes. Nanoscale 2020, 12, 6821-6831. [CrossRef] [PubMed]

84. Kravchyk, K.; Protesescu, L.; Bodnarchuk, M.I.; Krumeich, F.; Yarema, M.; Walter, M.; Guntlin, C.; Kovalenko, M.V. Monodisperse and Inorganically Capped $\mathrm{Sn}$ and $\mathrm{Sn} / \mathrm{SnO}_{2}$ Nanocrystals for High-Performance Li-Ion Battery Anodes. J. Am. Chem. Soc. 2013, 135, 4199-4202. [CrossRef] [PubMed]

85. Mourdikoudis, S.; Liz-Marzán, L.M. Oleylamine in Nanoparticle Synthesis. Chem. Mat. 2013, 25, 1465-1476. [CrossRef]

86. Wang, X.; Zhuang, J.; Peng, Q.; Li, Y. A general strategy for nanocrystal synthesis. Nature 2005, 437, 121-124. [CrossRef] [PubMed]

87. Peng, Z.A.; Peng, X. Formation of High-Quality CdTe, CdSe, and CdS Nanocrystals Using CdO as Precursor. J. Am. Chem. Soc. 2001, 123, 183-184. [CrossRef]

88. Núñez, N.; Sabek, J.; García-Sevillano, J.; Cantelar, E.; Escudero, A.; Ocaña, M. Solvent-Controlled Synthesis and Luminescence Properties of Uniform Eu: $\mathrm{YVO}_{4}$ Nanophosphors with Different Morphologies. Eur. J. Inorg. Chem. 2013, 2013, 1301-1309. [CrossRef]

89. Escudero, A.; Carrillo-Carrión, C.; Zyuzin, M.V.; Ashraf, S.; Hartmann, R.; Núñez, N.O.; Ocaña, M.; Parak, W.J. Synthesis and functionalization of monodisperse near-ultraviolet and visible excitable multifunctional $\mathrm{Eu}^{3+}, \mathrm{Bi}^{3+}: \mathrm{REVO}_{4}$ nanophosphors for bioimaging and biosensing applications. Nanoscale 2016, 8, 12221-12236. [CrossRef]

90. González-Mancebo, D.; Becerro, A.I.; Genevois, C.; Allix, M.; Corral, A.; Parrado-Gallego, A.; Ocaña, M. Structural, optical and $\mathrm{X}$-ray attenuation properties of $\mathrm{Tb}^{3+}: \mathrm{Ba}_{\mathrm{x}} \mathrm{Ce}_{1-\mathrm{x}} \mathrm{F}_{3-\mathrm{x}}(\mathrm{x}=0.18-0.48)$ nanospheres synthesized in polyol medium. Dalton Trans. 2018, 47, 8382-8391. [CrossRef] 
91. Jacob, D.S.; Bitton, L.; Grinblat, J.; Felner, I.; Koltypin, Y.; Gedanken, A. Are Ionic Liquids Really a Boon for the Synthesis of Inorganic Materials? A General Method for the Fabrication of Nanosized Metal Fluorides. Chem. Mat. 2006, 18, 3162-3168. [CrossRef]

92. Rodríguez-Liviano, S.; Núñez, N.O.; Rivera-Fernández, S.; de la Fuente, J.M.; Ocaña, M. Ionic Liquid Mediated Synthesis and Surface Modification of Multifunctional Mesoporous Eu:GdF 3 Nanoparticles for Biomedical Applications. Langmuir 2013, 29, 3411-3418. [CrossRef]

93. Tan, J.; Jin, X. Monodisperse, colloidal and luminescent calcium fluoride nanoparticles via a citrate-assisted hydrothermal route. J. Colloid Interface Sci. 2018, 531, 444-450. [CrossRef]

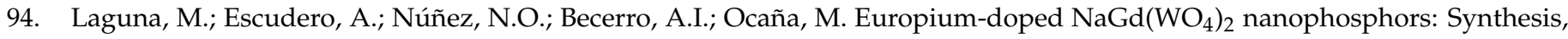
luminescence and their coating with fluorescein for $\mathrm{pH}$ sensing. Dalton Trans. 2017, 46, 11575-11583. [CrossRef] [PubMed]

95. Laguna, M.; Núñez, N.O.; Rodríguez, V.; Cantelar, E.; Stepien, G.; García, M.L.; de la Fuente, J.M.; Ocaña, M. Multifunctional Eu-doped $\mathrm{NaGd}\left(\mathrm{MoO}_{4}\right)_{2}$ nanoparticles functionalized with poly(l-lysine) for optical and MRI imaging. Dalton Trans. 2016, 45, 16354-16365. [CrossRef]

96. Papageorgiou, G.Z.; Papageorgiou, D.G.; Chrissafis, K.; Bikiaris, D.; Will, J.; Hoppe, A.; Roether, J.A.; Boccaccini, A.R. Crystallization and Melting Behavior of Poly(Butylene Succinate) Nanocomposites Containing Silica-Nanotubes and Strontium Hydroxyapatite Nanorods. Ind. Eng. Chem. Res. 2014, 53, 678-692. [CrossRef]

97. Papageorgiou, D.G.; Roumeli, E.; Chrissafis, K.; Lioutas, C.; Triantafyllidis, K.; Bikiaris, D.; Boccaccini, A.R. Thermal degradation kinetics and decomposition mechanism of PBSu nanocomposites with silica-nanotubes and strontium hydroxyapatite nanorods. Phys. Chem. Chem. Phys. 2014, 16, 4830-4842. [CrossRef] [PubMed]

98. Filippousi, M.; Siafaka, P.I.; Amanatiadou, E.P.; Nanaki, S.G.; Nerantzaki, M.; Bikiaris, D.N.; Vizirianakis, I.S.; Van Tendeloo, G. Modified chitosan coated mesoporous strontium hydroxyapatite nanorods as drug carriers. J. Mater. Chem. B 2015, 3, 5991-6000. [CrossRef]

99. Escudero, A.; Calvo, M.E.; Rivera-Fernández, S.; de la Fuente, J.M.; Ocaña, M. Microwave-Assisted Synthesis of Biocompatible Europium-Doped Calcium Hydroxyapatite and Fluoroapatite Luminescent Nanospindles Functionalized with Poly(acrylic acid). Langmuir 2013, 29, 1985-1994. [CrossRef] [PubMed]

100. Escudero, A.; Carrillo-Carrión, C.; Zyuzin, M.V.; Parak, W.J. Luminescent Rare-earth-based Nanoparticles: A Summarized Overview of their Synthesis, Functionalization, and Applications. Top. Curr. Chem. 2016, 374, 48. [CrossRef] [PubMed]

101. Escudero, A.; Becerro, A.I.; Carrillo-Carrion, C.; Núñez, N.; Zyuzin, M.V.; Laguna, M.; González-Mancebo, D.; Ocaña, M.; Parak, W.J. Rare earth based nanostructured materials: Synthesis, functionalization, properties and bioimaging and biosensing applications. Nanophotonics 2017, 6, 881-921. [CrossRef]

102. Escudero, A.; Moretti, E.; Ocaña, M. Synthesis and luminescence of uniform europium-doped bismuth fluoride and bismuth oxyfluoride particles with different morphologies. CrystEngComm 2014, 16, 3274-3283. [CrossRef]

103. Silvert, P.-Y.; Herrera-Urbina, R.; Duvauchelle, N.; Vijayakrishnan, V.; Elhsissen, K.T. Preparation of colloidal silver dispersions by the polyol process. Part 1-Synthesis and characterization. J. Mater. Chem. 1996, 6, 573-577. [CrossRef]

104. Rabenau, A. The Role of Hydrothermal Synthesis in Preparative Chemistry. Angew. Chem. Int. Ed. Engl. 1985, 24, 1026-1040. [CrossRef]

105. Schäf, O.; Ghobarkar, H.; Knauth, P. Hydrothermal Synthesis of Nanomaterials. In Nanostructured Materials: Selected Synthesis Methods Properties and Applications; Knauth, P., Schoonman, J., Eds.; Springer: Boston, MA, USA, 2002; pp. $23-41$.

106. Morris, R.E. Ionothermal synthesis-ionic liquids as functional solvents in the preparation of crystalline materials. Chem. Commun. 2009, 2990-2998. [CrossRef]

107. Parnham, E.R.; Morris, R.E. Ionothermal Synthesis of Zeolites, Metal-Organic Frameworks, and Inorganic-Organic Hybrids. Acc. Chem. Res. 2007, 40, 1005-1013. [CrossRef]

108. Xu, C.; De, S.; Balu, A.M.; Ojeda, M.; Luque, R. Mechanochemical synthesis of advanced nanomaterials for catalytic applications. Chem. Commun. 2015, 51, 6698-6713. [CrossRef]

109. Maurin, G.; Serre, C.; Cooper, A.; Férey, G. The new age of MOFs and of their porous-related solids. Chem. Soc. Rev. 2017, 46, 3104-3107. [CrossRef]

110. Li, H.; Eddaoudi, M.; O'Keeffe, M.; Yaghi, O.M. Design and synthesis of an exceptionally stable and highly porous metal-organic framework. Nature 1999, 402, 276-279. [CrossRef]

111. Zhou, H.-C.; Long, J.R.; Yaghi, O.M. Introduction to Metal-Organic Frameworks. Chem. Rev. 2012, 112, 673-674. [CrossRef]

112. Zhou, H.-C.J.; Kitagawa, S. Metal-Organic Frameworks (MOFs). Chem. Soc. Rev. 2014, 43, 5415-5418. [CrossRef] [PubMed]

113. Furukawa, H.; Cordova, K.E.; O’Keeffe, M.; Yaghi, O.M. The Chemistry and Applications of Metal-Organic Frameworks. Science 2013, 341, 1230444. [CrossRef] [PubMed]

114. Li, J.-R.; Sculley, J.; Zhou, H.-C. Metal-Organic Frameworks for Separations. Chem. Rev. 2012, 112, 869-932. [CrossRef] [PubMed]

115. Li, H.; Wang, K.; Sun, Y.; Lollar, C.T.; Li, J.; Zhou, H.-C. Recent advances in gas storage and separation using metal-organic frameworks. Mater. Today 2018, 21, 108-121. [CrossRef]

116. Li, H.; Li, L.; Lin, R.-B.; Zhou, W.; Zhang, Z.; Xiang, S.; Chen, B. Porous metal-organic frameworks for gas storage and separation: Status and challenges. EnergyChem 2019, 1, 100006. [CrossRef]

117. Liu, G.; Chernikova, V.; Liu, Y.; Zhang, K.; Belmabkhout, Y.; Shekhah, O.; Zhang, C.; Yi, S.; Eddaoudi, M.; Koros, W.J. Mixed matrix formulations with MOF molecular sieving for key energy-intensive separations. Nat. Mater. 2018, 17, 283-289. [CrossRef] 
118. Qiu, T.; Liang, Z.; Guo, W.; Tabassum, H.; Gao, S.; Zou, R. Metal-Organic Framework-Based Materials for Energy Conversion and Storage. ACS Energy Lett. 2020, 5, 520-532. [CrossRef]

119. Li, H.-Y.; Zhao, S.-N.; Zang, S.-Q.; Li, J. Functional metal-organic frameworks as effective sensors of gases and volatile compounds. Chem. Soc. Rev. 2020, 49, 6364-6401. [CrossRef]

120. Lee, J.; Farha, O.K.; Roberts, J.; Scheidt, K.A.; Nguyen, S.T.; Hupp, J.T. Metal-organic framework materials as catalysts. Chem. Soc. Rev. 2009, 38, 1450-1459. [CrossRef]

121. Horcajada, P.; Chalati, T.; Serre, C.; Gillet, B.; Sebrie, C.; Baati, T.; Eubank, J.F.; Heurtaux, D.; Clayette, P.; Kreuz, C.; et al. Porous metal-organic-framework nanoscale carriers as a potential platform for drug delivery and imaging. Nat. Mater. 2010, 9, 172-178. [CrossRef]

122. Wuttke, S.; Lismont, M.; Escudero, A.; Rungtaweevoranit, B.; Parak, W.J. Positioning metal-organic framework nanoparticles within the context of drug delivery-A comparison with mesoporous silica nanoparticles and dendrimers. Biomaterials 2017, 123, 172-183. [CrossRef]

123. Anstoetz, M.; Rose, T.J.; Clark, M.W.; Yee, L.H.; Raymond, C.A.; Vancov, T. Novel Applications for Oxalate-Phosphate-Amine Metal-Organic-Frameworks (OPA-MOFs): Can an Iron-Based OPA-MOF Be Used as Slow-Release Fertilizer? PLoS ONE 2015, 10, e0144169. [CrossRef]

124. Forgan, R.S. Modulated self-assembly of metal-organic frameworks. Chem. Sci. 2020, 11, 4546-4562. [CrossRef] [PubMed]

125. Kirchon, A.; Feng, L.; Drake, H.F.; Joseph, E.A.; Zhou, H.-C. From fundamentals to applications: A toolbox for robust and multifunctional MOF materials. Chem. Soc. Rev. 2018, 47, 8611-8638. [CrossRef] [PubMed]

126. Chung, Y.G.; Haldoupis, E.; Bucior, B.J.; Haranczyk, M.; Lee, S.; Zhang, H.; Vogiatzis, K.D.; Milisavljevic, M.; Ling, S.; Camp, J.S.; et al. Advances, Updates, and Analytics for the Computation-Ready, Experimental Metal-Organic Framework Database: CoRE MOF 2019. J. Chem. Eng. Data 2019, 64, 5985-5998. [CrossRef]

127. Férey, G.; Haouas, M.; Loiseau, T.; Taulelle, F. Nanoporous Solids: How Do They Form? An In Situ Approach. Chem. Mat. 2014, 26, 299-309. [CrossRef]

128. Biswal, D.; Kusalik, P.G. Probing Molecular Mechanisms of Self-Assembly in Metal-Organic Frameworks. ACS Nano 2017, 11, 258-268. [CrossRef] [PubMed]

129. Kollias, L.; Cantu, D.C.; Tubbs, M.A.; Rousseau, R.; Glezakou, V.-A.; Salvalaglio, M. Molecular Level Understanding of the Free Energy Landscape in Early Stages of Metal-Organic Framework Nucleation. J. Am. Chem. Soc. 2019, 141, 6073-6081. [CrossRef]

130. Xing, J.; Schweighauser, L.; Okada, S.; Harano, K.; Nakamura, E. Atomistic structures and dynamics of prenucleation clusters in MOF-2 and MOF-5 syntheses. Nat. Commun. 2019, 10, 3608. [CrossRef] [PubMed]

131. Giménez-Marqués, M.; Hidalgo, T.; Serre, C.; Horcajada, P. Nanostructured metal-organic frameworks and their bio-related applications. Coord. Chem. Rev. 2016, 307, 342-360. [CrossRef]

132. Wang, Q.; Astruc, D. State of the Art and Prospects in Metal-Organic Framework (MOF)-Based and MOF-Derived Nanocatalysis. Chem. Rev. 2020, 120, 1438-1511. [CrossRef]

133. Feng, L.; Wang, K.-Y.; Powell, J.; Zhou, H.-C. Controllable Synthesis of Metal-Organic Frameworks and Their Hierarchical Assemblies. Matter 2019, 1, 801-824. [CrossRef]

134. Wang, S.; McGuirk, C.M.; d’Aquino, A.; Mason, J.A.; Mirkin, C.A. Metal-Organic Framework Nanoparticles. Adv. Mater. 2018, 30, 1800202. [CrossRef] [PubMed]

135. Carné, A.; Carbonell, C.; Imaz, I.; Maspoch, D. Nanoscale metal-organic materials. Chem. Soc. Rev. 2011, 40, 291-305. [CrossRef] [PubMed]

136. Pan, Y.; Heryadi, D.; Zhou, F.; Zhao, L.; Lestari, G.; Su, H.; Lai, Z. Tuning the crystal morphology and size of zeolitic imidazolate framework-8 in aqueous solution by surfactants. CrystEngComm 2011, 13, 6937-6940. [CrossRef]

137. Schejn, A.; Balan, L.; Falk, V.; Aranda, L.; Medjahdi, G.; Schneider, R. Controlling ZIF-8 nano- and microcrystal formation and reactivity through zinc salt variations. CrystEngComm 2014, 16, 4493-4500. [CrossRef]

138. Umemura, A.; Diring, S.; Furukawa, S.; Uehara, H.; Tsuruoka, T.; Kitagawa, S. Morphology Design of Porous Coordination Polymer Crystals by Coordination Modulation. J. Am. Chem. Soc. 2011, 133, 15506-15513. [CrossRef] [PubMed]

139. Koh, K.; Wong-Foy, A.G.; Matzger, A.J. MOF@MOF: Microporous core-shell architectures. Chem. Commun. 2009, 6162-6164. [CrossRef] [PubMed]

140. Tang, J.; Salunkhe, R.R.; Liu, J.; Torad, N.L.; Imura, M.; Furukawa, S.; Yamauchi, Y. Thermal Conversion of Core-Shell MetalOrganic Frameworks: A New Method for Selectively Functionalized Nanoporous Hybrid Carbon. J. Am. Chem. Soc. 2015, 137, 1572-1580. [CrossRef]

141. Avci, C.; Ariñez-Soriano, J.; Carné-Sánchez, A.; Guillerm, V.; Carbonell, C.; Imaz, I.; Maspoch, D. Post-Synthetic Anisotropic Wet-Chemical Etching of Colloidal Sodalite ZIF Crystals. Angew. Chem. Int. Edit 2015, 54, 14417-14421. [CrossRef]

142. Rubio-Martinez, M.; Avci-Camur, C.; Thornton, A.W.; Imaz, I.; Maspoch, D.; Hill, M.R. New synthetic routes towards MOF production at scale. Chem. Soc. Rev. 2017, 46, 3453-3480. [CrossRef]

143. Khan, N.A.; Jhung, S.H. Synthesis of metal-organic frameworks (MOFs) with microwave or ultrasound: Rapid reaction, phaseselectivity, and size reduction. Coord. Chem. Rev. 2015, 285, 11-23. [CrossRef]

144. Friščić, T. Metal-Organic Frameworks: Mechanochemical Synthesis Strategies. In Encyclopedia of Inorganic and Bioinorganic Chemistry; John Wiley \& Sons: Hoboken, NJ, USA, 2014; pp. 1-19. 
145. Liu, Z.; Zhu, J.; Peng, C.; Wakihara, T.; Okubo, T. Continuous flow synthesis of ordered porous materials: From zeolites to metal-organic frameworks and mesoporous silica. React. Chem. Eng. 2019, 4, 1699-1720. [CrossRef]

146. Danks, A.E.; Hall, S.R.; Schnepp, Z. The evolution of 'sol-gel' chemistry as a technique for materials synthesis. Mater. Horiz. 2016, 3, 91-112. [CrossRef]

147. Debecker, D.P.; Mutin, P.H. Non-hydrolytic sol-gel routes to heterogeneous catalysts. Chem. Soc. Rev. 2012, 41, 3624-3650. [CrossRef] [PubMed]

148. Abutbul, R.E.; Golan, Y. 'Beneficial impurities' in colloidal synthesis of surfactant coated inorganic nanoparticles. Nanotechnology 2021, 32, 102001. [CrossRef] [PubMed] 